\title{
Development of Neem Capsule via Biopolymer and Natural Rubber for Its Controlled Release
}

\author{
Sa-Ad Riyajan \\ Department of Materials Science and Technology, \\ Faculty of Science, Prince of Songkla University
}

Thailand

\section{Introduction}

At present, population of world is over 6900 million persons, therefore food product is vital. Fig.1 shows the vegetable and fruits such as rice, orange and strawberry.
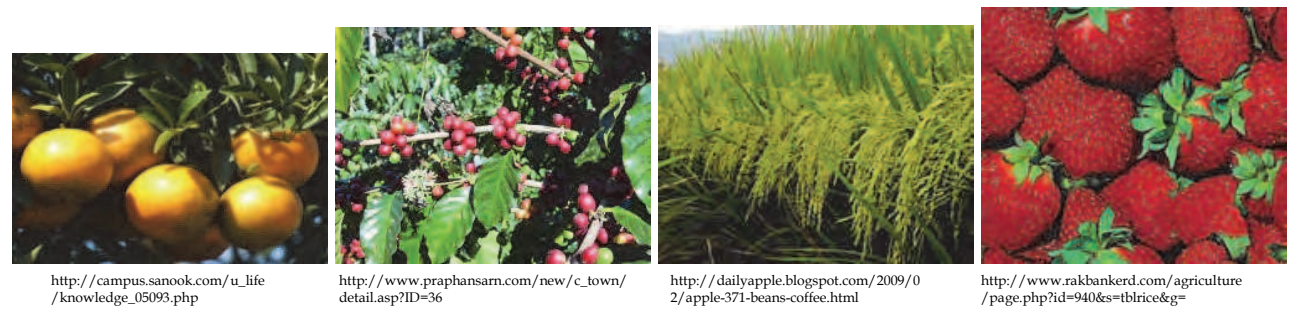

Fig. 1. Photograph of rice and fruits.

The utilization of synthetic pesticides in the world started in the 1935 and became widespread after World War II. By 1950, pesticide was found to increase farm yield far beyond pre-World War II levels (Nazir Javed et al., 2007).

Farmers depend heavily on synthetic pesticides to control insects in their crops. Today, it is one of the most commonly used approaches in controlling insects but it is relatively high in toxicity and have high environmental impact. At present, natural pesticide is applied thus to solve this problem due to no residue toxic chemical reagent on environment.

Neem is a tree as shown in Fig.2 and is widely distributed in South Asia, South-East Asia, and some other tropical areas, especially in Thailand (Nazir Javed et al., 2007; Kreutzweiser et al., 2004; Wei-Hong \& Zhan-Qian, 2006; Kulkami et al., 2001; Kumbarn et al. , 1999; Sundaram \& Curry, 1996). The neem seed kernels as presenting in Fig. 3 contains Azadiracthin-A (Aza-A), which is the major insecticidal tetranortriterpinoid. Neem Aza-A is a powerful insect antifeedant and growth-regulating substance, exhibiting considerable promise as an insecticide (Nazir Javed et al., 2007). It can control at least 200 species of agriculture and storage insect pest belonging to different orders, but it has short environmental persistence, and causes negligible hazard to nontarget organisms including humans. Fig. 4 shows insects destroying the vegetable. Its short environmental persistence is due to the presence of sensitive moieties such as $p$-electrons, ester linkages, and epoxide 
ring. Thus, neem Aza-A is highly photolabile, either breaking down or isomerizing under sunlight. However, the photodegradation of neem Aza-A in sunlight is the major problem limiting its use in agriculture because the insecticide should persist long enough to cause the death of the insect. Many works solve this problem. The controlled stability of neem containing Aza-A can be done the two major approaches such as addition of antioxidant in neem solution and encapsulation of neem by polymer metric. For example, the addition of UV light absorbers can enhance the photostability of neem Aza-A (Wei-Hong \& Zhan-Qian, 2006). The addition of ferulic acid, gallic acid, and rutin provided a moderate degree of photostabilization of neem Aza-A (Wei-Hong \& Zhan-Qian, 2006). The present patent invention relates to an improved granular formulation of neem seed extract containing neem Aza-A having enhanced storage stability (Sreenivasa et al., 2006), and the ability for gradual release of neem Aza-A for application to plant rhizosphere. The formulation consist of inert particulate as a carrier at least one lipophilic substance as a deactivator/binder, optional colorant and neem seed extract containing neem Aza-A.

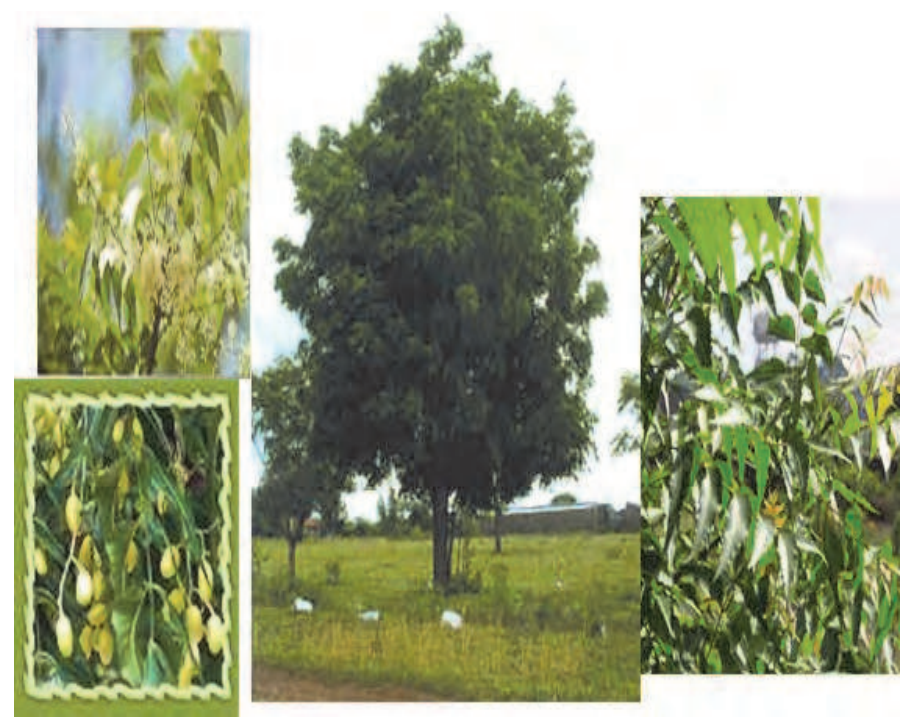

Fig. 2. Images of neem tree and it fruits

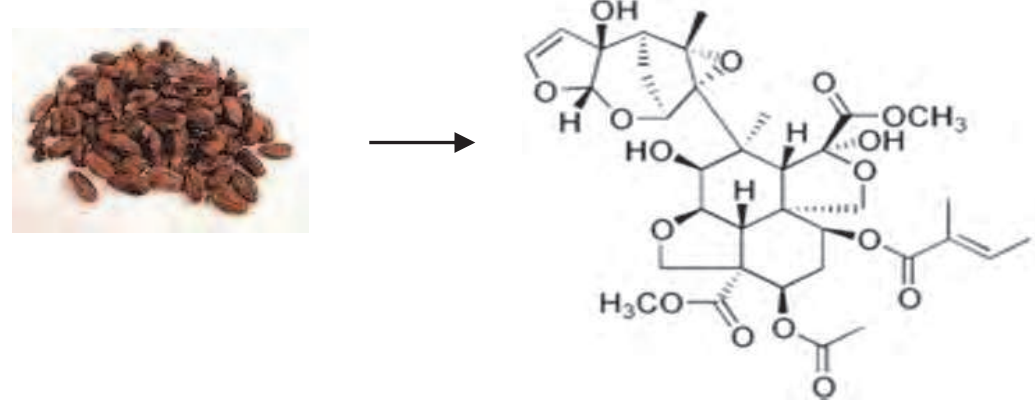

Fig. 3. Neem seed and chemical structure of Azadirachtin 
By the way, detail of preparing neem etracted is reported as following (Riyajan \& Sakdapipanich, 2009) neem seed kernels (5 g) had their cortex removed then crushed into small pieces, deoiled by grinding in light petroleum $(200 \mathrm{~mL})$ and filtered. The grinding and filtering were repeated twice more. The deoiled neem seed powder was stirred in $200 \mathrm{~mL}$ of methanol for $2 \mathrm{~h}$ and filtered at room temperature. The meal was reextrated with two further portions of methanol. The combined methanol filtrates were concentrated to approximately $50 \mathrm{~mL}$, the aqueous methanol solution was extracted thrice with an equal volume of n-hexane (each was $50 \mathrm{~mL}$ ) followed by $3 \times 50 \mathrm{ml}$ of dichloromethane (Fluka Company). The methanol-water layer was discarded and the dichlormethane layers were combined and dried over $\mathrm{MgSO}_{4}$ (Fluka Company) and then evaporated to dryness. Two grams of the product were dissolved in eight $\mathrm{mL}$ of hexane during stirring. The liquid was separated into two layers using a separating funnel. The process was repeated by addition of a further $8 \mathrm{~mL}$ of ether. The methanol layer was evaporated and the residue was dissolved in $2 \mathrm{~mL}$ dichloromethane and then treated with $10 \mathrm{~mL}$-hexane and $10 \mathrm{~mL}$ ether, according to the above-mentioned process. The final yield of $65.0 \%$ neem Aza-A was $0.8 \mathrm{~g}$ from $1 \mathrm{~kg}$ of neem seeds.

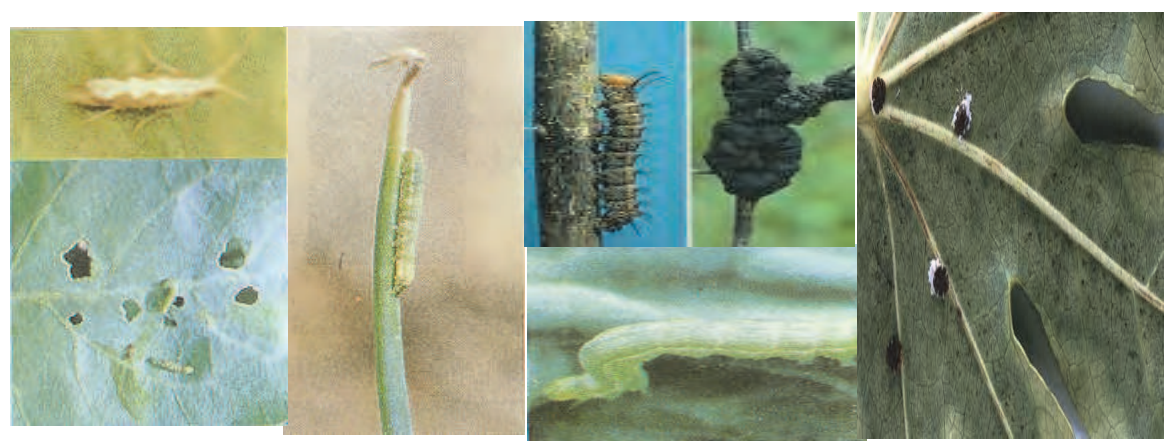

Fig. 4. Photograms of insects destroying the vegetables

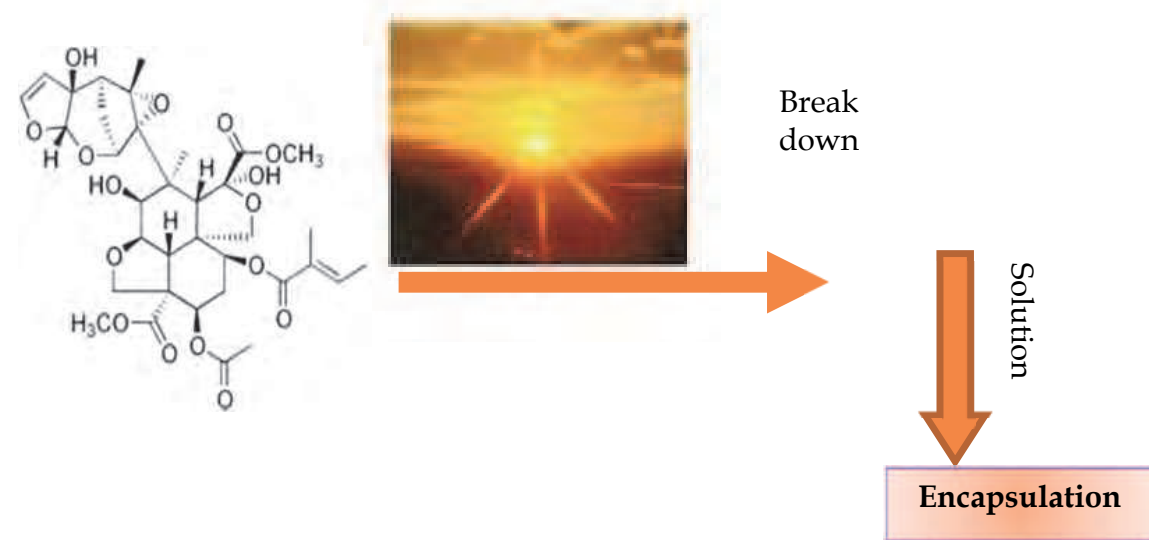

Fig. 5. Formula structure of Azadirachtin break down or isomerize under sunlight 


\section{Encapsulation}

The encapsulation is packages the sensitive ingredients within a coating or wall material (Burt et al., 1995; Kim \& Jung, 2007; Kulkarni et al., 2000; Fundueanu et al., Ruan et al., 2002; Sun et al., 2008; Vanderaer et al., 1974; Zhu \& Zhuo, 2001). Definition of encapsulation is process in which particles or droplets/gases are surrounded by a coating of polymers to give capsules many useful properties. The capsules consisting of a core and a permeable or non-permeable wall have been widely used in release and transfer control. The wall material protects the sensitive ingredient (or core) including catalysts, drugs, anti-fouling compounds or toners, against adverse reactions, prevents the loss of volatile ingredients, and can control the rate of release of the ingredient. In addition, microencapsulation can convert liquids into free-flowing powders, so that they can be more easily handled. The controlled release of the capsule contents strongly depends on capsule wall thickness and porosity (Ji et al., 2001). The model of encapsulation is presented in Fig. 6. Rate of reactive agent release from capsule two patterns is presented in Fig.7. It is clear that the reactive agent from capsule obtained from matrix model start to release faster than that of capsule derived from encapsulate model.

\section{Polymer type}

Polymers using the encapsulated neem made from synthetic polymer and natural polymer. For example, the synthetic polymers are given poly (vinyl alcohol) (PVA), polyethylene glycol and polyacrylamide. In case of natural polymer, they are obtained from chitosan, sodium alginate, cellulose, natural rubber (NR) and starch. NR is used a membrane of capsule for this work due to its hydrophobic behaviors. It consists of 1,4-cis polyisoprene and non-rubber component such as protein, carbohydrate and fatty acid (Riyajan \& Santipanusopon, 2010)

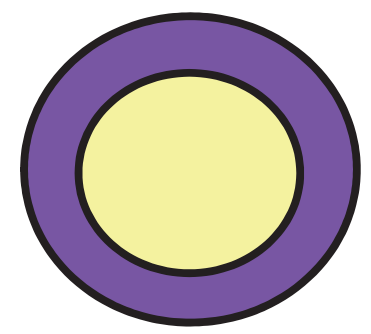

Encapsulation

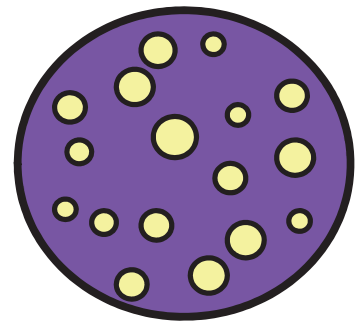

Matrix model

Fig. 6. Model of encapsulation consisting of encapsulation and matrix

\section{Crosslinking agent}

The chemicals of the crossliking agent are glutaraldehyde, calcium chloride and maleic anhydride.

\section{The methods for manufacture microcapsules}

The methods for manufacture microcapsules are physical method, physical-chemical method and chemical method as following. 

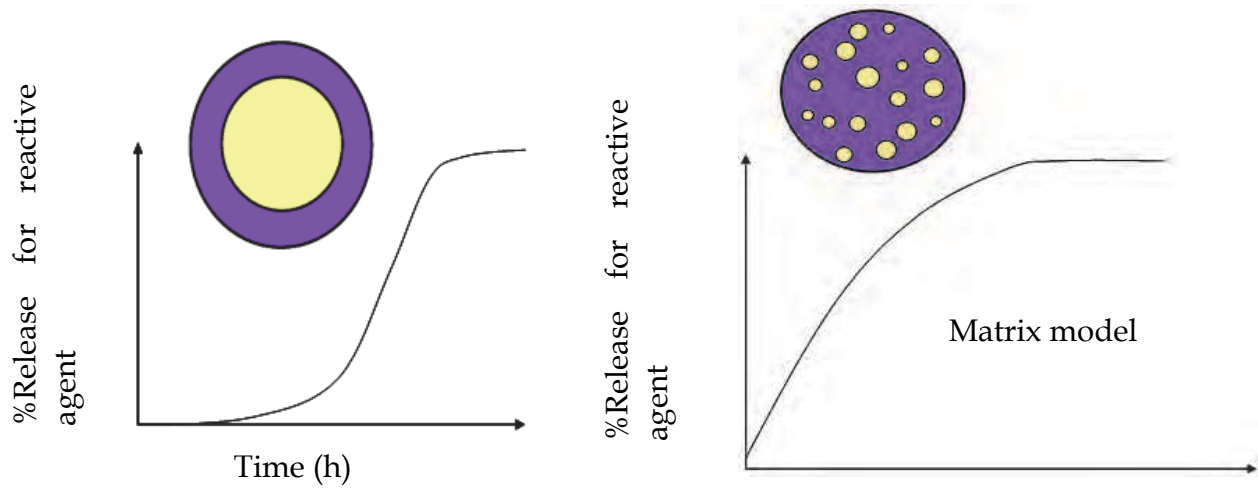

Time (h)

Fig. 7. Rate of reactive agent release of different capsules from encapsulation model and matrix model

\section{Physical methods}

\section{Pan coating}

The pan coating process is widely used in the preparing capsule application and it is presented in Fig.8. The reactive particles are tumbled in a pan or other device while the coating material is applied slowly to get the capsule. For example, (the nitrate solution is the coating of fertilizers by degradable polymers. The water vapour and liquid diffuse through polymer films detached from their support. Therefore, we may classify polymers as a function of their properties like water vapour and liquid barrier. The capsule of fertilizer was done by pan coating. The electron microscopy used to see the quality of the wall has showed the presence of pores due to the rapid evaporation of solvent. A drying in air current and an annealing could be done to avoid this problem (Devassine et al., 2002).
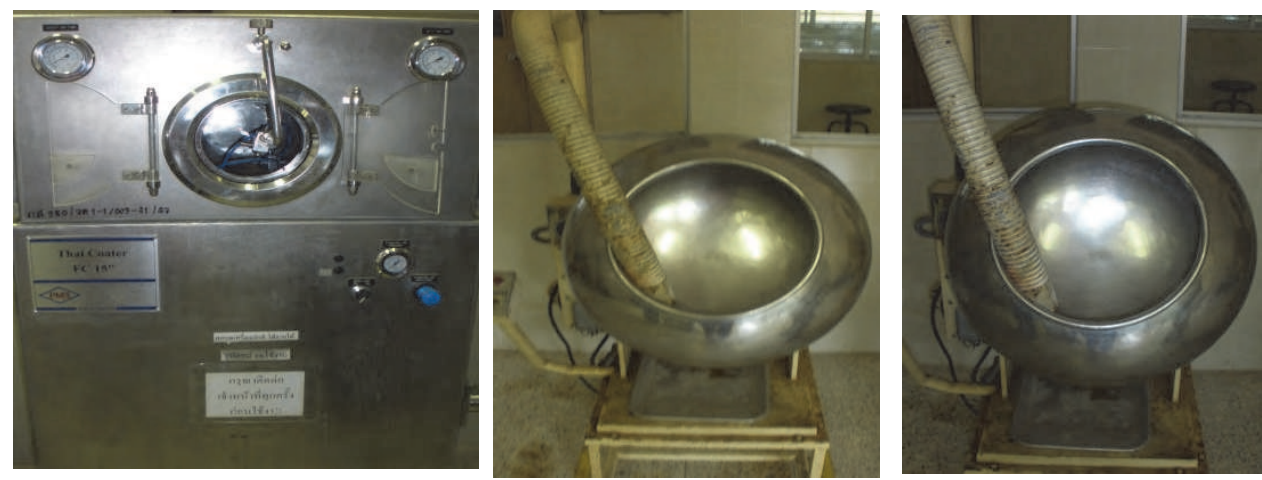

Fig. 8. Photographs of pan coating equipment from digital camera

\section{Fluidized bed process}

Fluidized bed process or air-suspension coating of reactive particles by solutions or melts gives better control and flexibility. Fig. 9 presents the photographs of the fluidized bed 
process. The reactive agent particles are coated while suspended in an upward-moving air stream. They are supported by a perforated plate having different patterns of holes inside and outside a cylindrical insert. Most of the rising air (usually heated) flows inside the cylinder, causing the particles to rise rapidly. Micro encapsulation by air suspension technique consist of the dispersing of solid, particulate core materials in a supporting air stream and the spray coating on the air suspended particles. The advantage of the fluidized bed technology is well known for its good solid mixing properties leading to lower agglomeration tendency, as well as its good heat and mass transfer rates and an uniform temperature distribution leading to the petrochemical industry (since decades) as well as in the pharmaceutical and food industry (Rosenkranza et al., 2008).

\section{Spray-drying}

Spray drying is used in preparing capsule and it demonstrates in Fig. 10 when an active material is dissolved or suspended in a melt or polymer solution and becomes trapped in the dried particle. The main advantage is the ability to handle labile materials because of the short contact time in the dryer, in addition, the operation is economical. In modern spray dryers the viscosity of the solutions to be sprayed. The main factors that affect encapsulation efficiency of capsule obtained form spraying techniques the type of wall material, the properties of the core materials (concentration, volatility), the characteristics of the infeed emulsion (total solids, viscosity, droplets size) and the conditions of the spray drying process including atomization type, inlet air temperature, air flow and humidity.
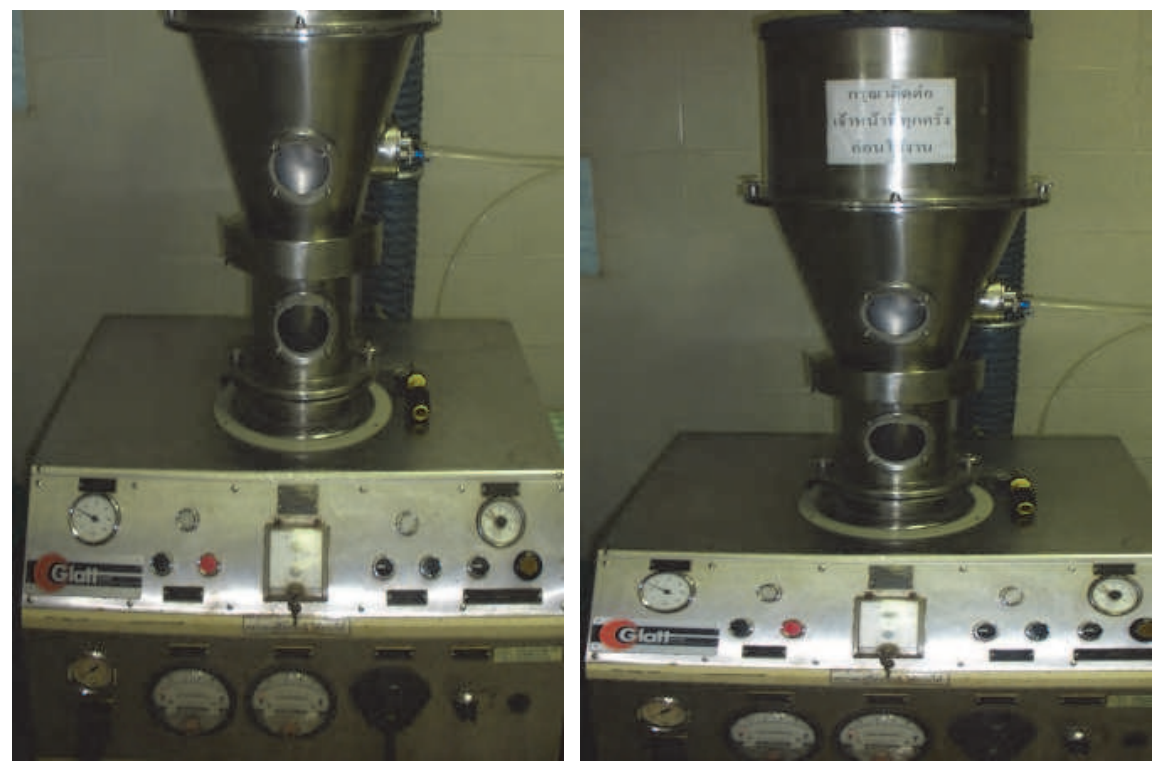

Fig. 9. Photographs of the fluidized bed process from digital camera

The main advantage of spray dryer is the ability to handle labile materials because of the short contact time in the dryer, in addition, the operation is economical. In modern spray dryers the viscosity of the solutions to be sprayed. However, disadvantage of this method is degradation of reactive agent. 


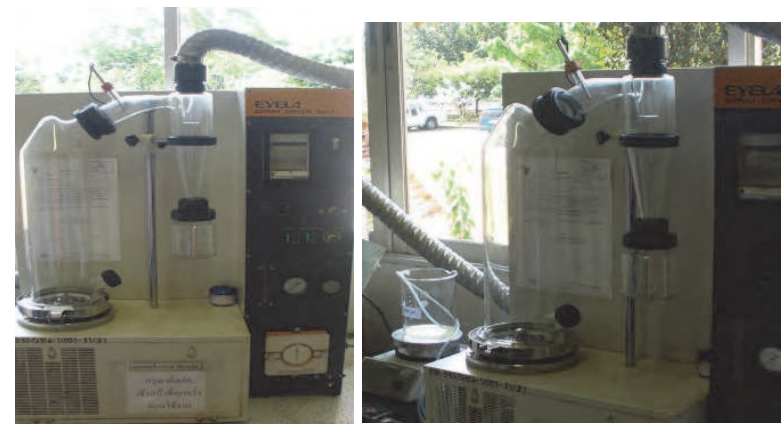

Fig. 10. Photographs of spray drying from digital camera

Physical-chemical method

Coacervate is a technique which consists of a tiny spherical droplet of assorted organic polymer molecules helding together by hydrophobic forces from a surrounding liquid. The particle size of droplet from coacervates method is range of 1 to 100 micrometers across which there is osmotic properties and form spontaneously from certain dilute organic solutions.

\section{Chemical methods}

\section{Interfacial polycondensation}

The two reactants in a condensation interface and react rapidly. Under the right conditions, thin flexible walls form rapidly at the interface. Interfacial polycondensation is a method of wide applicability for encapsulation of active ingredients. It offers the possibility of rapid production of polymers, under normal conditions of temperature and pressure, in an almost ready-to-use form. However, the mechanistic aspects of the process are not well understood because of the difficulties in following the fast kinetics and the need to account for the interplay of several equilibrium and rate processes in any comprehensive modeling effort.

The factors on properties of capsule obtained from interfacial polymerization are monomer concentration, diffusion and interfacial reaction. A solution of the pesticide and a diacid chloride are emulsified in water and an aqueous solution containing an amine and a polyfunctional isocynate is added. Base is present to neutralize the acid formed during the reaction. Condensed polymer walls form instantaneously at the interface of the emulsion droplets. Considering, the different physicochemical rate and equilibrium processes of this capsule (Dhumala et al., 2008) are (i) ionic equilibria for the aqueous phase monomer, (ii) transport of the aqueous phase monomer and/or the organic phase monomer from bulk phases to the site of reaction, (iii) the reaction between the two monomers, and finally and (iv) the phase separation of the formed oligomeric species.

\section{Interfacial cross-linking}

Interfacial cross-linking is derived from interfacial polycondensation, and was developed to avoid the use of toxic diamines, for health applications. In this method, the small bifunctional monomer containing active hydrogen atoms is replaced by a biosourced polymer, like a chitosan. When the reaction is performed at the interface of an emulsion, the acid chloride reacts with the various functional groups of the protein, leading to the formation of a membrane. The cross-linked protein microcapsules are biocompatible and 
biodegradable, and the presence of the protein backbone renders the membrane more resistant and elastic than those obtained by interfacial polycondensation. The method is very versatile, and the properties of the microcapsules (size, porosity, degradability, mechanical and resistance) can be easily tuned by varying the preparation parameters. A carbohydrate can be added to the protein, for the modulation of particle biodegradability. For example, the thermoresponsive properties of the macromers are imparted by $\mathrm{N}$-isopropylacrylamide, with additional co-monomers including pentaerythritol diacrylate monostearate, acrylamide and hydroxyethyl acrylate (Klouda et al., 2011). The latter monomer contains hydroxyl groups that can be modified to acrylate or methacrylate moieties. These moieties can be covalently cross-linked with the addition of a water soluble, thermal free radical initiator system. Increased stability and higher viscosity values could be achieved when the hydrogels were physically and chemically gelled, as opposed to only thermally gelled controls.

\section{In-situ polymerization}

In a few microencapsulation processes, the direct polymerization of a single monomer carried out on the particle surface. Usual deposition rates are about $0.5 \mu \mathrm{m} / \mathrm{min}$. Coating thickness ranges $0.2-75 \mu \mathrm{m}(0.0079-3.0 \mathrm{mils})$. The coating is uniform, even over sharp projections. For, example, aluminum pigment was encapsulated with styrene-maleic acid copolymer by in situ polymerization (Liu et al., 2008a). In addition, poly(trimethylolpropane triacrylate)/flaky aluminum composite particle (PTMPTA/Al) was prepared by in situ polymerization in order to improve the corrosion resistance and adhesive performance of aluminum pigments (Liu et al., 2008a).

\section{Mechanism of release}

The methods of reactive agent release from capsule are erosion of polymer, diffusion and stress driven. Fig.11 represents the release pattern of reactive agent from capsule in medium. Even when the aim of a microencapsulation application is the isolation of the core from its surrounding, the wall must be ruptured at the time of use. Many walls are ruptured easily by pressure or shear stress, as in the case of breaking dye particles during writing to form a copy. Capsule contents may be released by melting the wall, or dissolving it under particular conditions, as in the case of an enteric drug coating. In other systems, the wall is broken by solvent action, enzyme attack, chemical reaction, hydrolysis, or slow disintegration. The capsule made from polylactic acid, polyglycolic acid and their polymer slowly biodegrade in nature. Encapsulation can be used to slow the release of a drug into the environment. This may permit one controlled release dose to substitute for several doses of non-encapsulated drug and also may decrease toxic side effects for some drugs by preventing high initial concentrations in the medium. There is usually a certain desired release pattern. In some cases, it is zero-order, i.e. the release rate is constant. In this case, the microcapsules deliver a fixed amount of drug per minute or hour during the period of their effectiveness. This can occur as long as a solid reservoir or dissolving drug is maintained in the microcapsule. A more typical release pattern is first-order in which the rate decreases exponentially with time until the drug source is exhausted. In this situation, a fixed amount of drug is in solution inside the microcapsule. The concentration difference between the inside and the outside of the capsule decreases continually as the drug diffuses. 


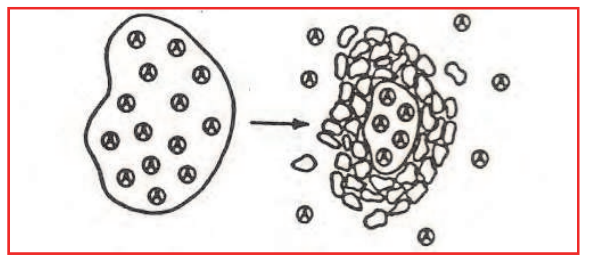

Degradation-controlled monolithic system

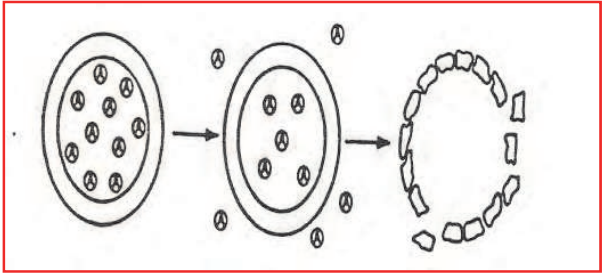

Diffusion-controlled reservoir systems

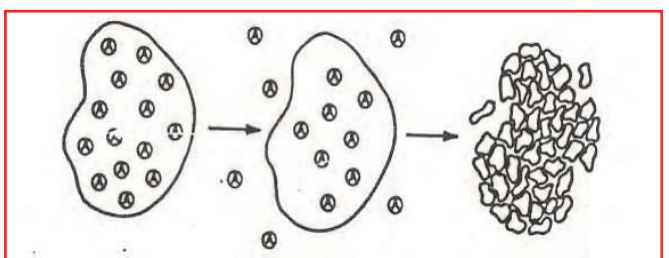

Diffusion-controlled monolithic systems

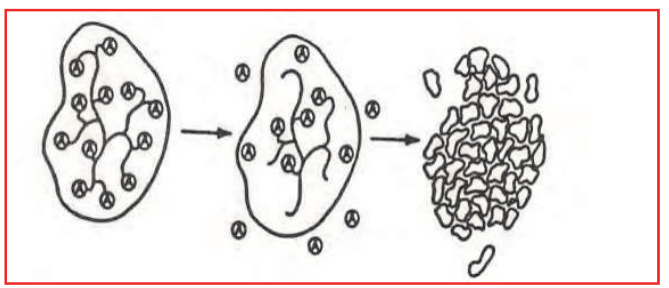

Erodable polyagent systems

Fig. 11. Possible mechanism of release pattern of reactive agent from capsule (Baker 2000)

\section{Mechanism of reactive lease from capsule}

A coacervate is a technique, which consists of a tiny spherical droplet of assorted organic polymer molecules helding together by hydrophobic forces from a surrounding liquid. The particle size of droplet from coacervates method is range of 1 to 100 micrometers across which there is osmotic properties and form spontaneously from certain dilute organic solutions.

\section{Preparation of capsule}

The two preparing capsules were coaservation and spray drying as following.

\section{i. Coaseveration}

A $4 \%$ sodium alginate solution in distilled water was prepared by heating mental. After complete cooling the amounts of neem Aza-A (7000 ppm) was added and mixed thoroughly using a magnetic stirrer. The polymer solution containing neem Aza-A was added dropwise into methanol containing $1 \%$ glutaraldehyde (GA) and $1 \%$ of $1 \mathrm{~N} \mathrm{HCl}$, using a $25-\mathrm{ml}$ hypodermic syringe $(0.8 \mathrm{~mm}$ diameter $)$ with constant stirring. The beads formed were removed from methanol at a selected time interval say 10, 20 and $30 \mathrm{~min}$. The beads were washed with water and then dried. Fig.12 shows procedure of preparing capsule neem obtained from coaservation. The efficiency of entrapment was calculated as the ratio between the initial mass of neem Aza-A to be encapsulated and its mass in the final product. About 20 mg of exactly weighed microcapsule sample was extracted in distilled water to form a homogeneous solution. The total neem Aza-A in the solution was extracted for $48 \mathrm{~h}$ with a $50 / 50 \mathrm{MeOH} / \mathrm{H}_{2} \mathrm{O}$ mixture and its mass was determined by HPLC (PerkinElmer LC).

\section{Drying rate study of the beads}

A 3 samples of the beads formed after crosslinking with GA were selected for the drying study and were allowed to dry in an oven (VELP) maintained at $31 \pm 2{ }^{\circ} \mathrm{C}$ (the initial mass of the beads should be nearly equal). The masses of the beads were taken at definite intervals of time until the constant mass was achieved. All the mass measurements were done on a 
Mettler single pan balance (Model AB 204, Mettler). In order to obtain reproducible results, experiments were conducted in triplicate, and the average values were used for the calculation and plotting of the data vs. time. Results of drying are displayed in Fig. 13 indicate that the beads with longer time of exposure to the crosslinking agent exhibit higher drying rates than the beads exposed to shorter time to glutaraldehyde. The beads exposed for 10 min dried quickly (i.e., within $40 \mathrm{~h}$ ) when compared to beads exposed to the crosslinking agent for $30 \mathrm{~min}$ (i.e., $72 \mathrm{~h}$ ), while an intermediary drying time (i.e. $60 \mathrm{~h}$ ) was required by the beads exposed to crosslinking for $20 \mathrm{~min}$. This may be due to an increased rigidity of the polymer formed after a longer exposure time to the crosslinking agent thereby showing a decreased desorption rate of liquid from the beads.

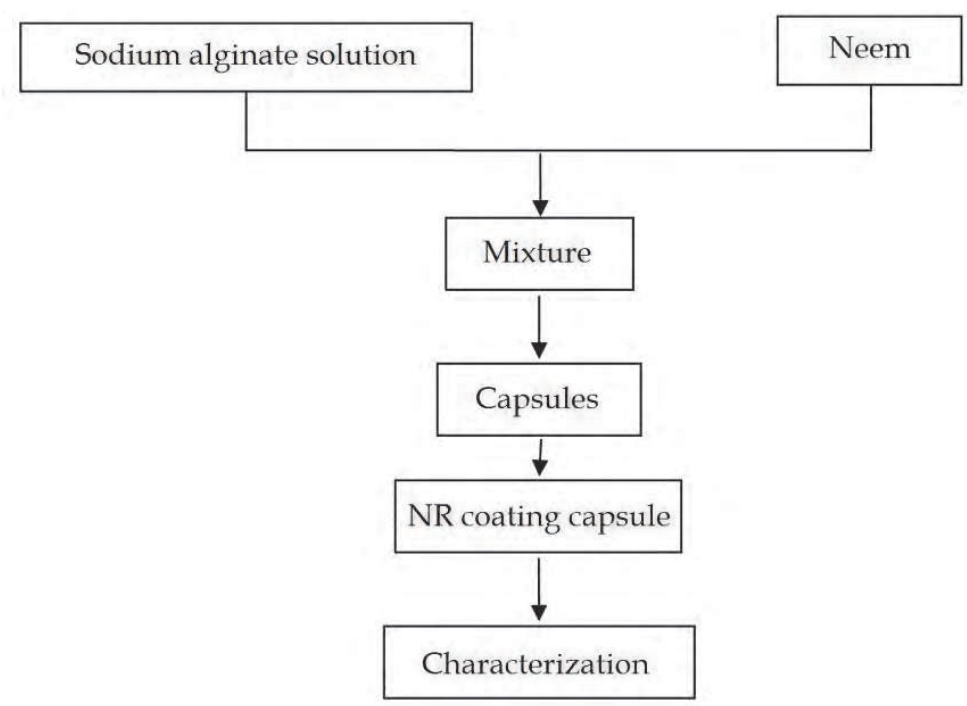

Fig. 12. Procedure of preparing capsule neem Aza-A obtained from coaservation

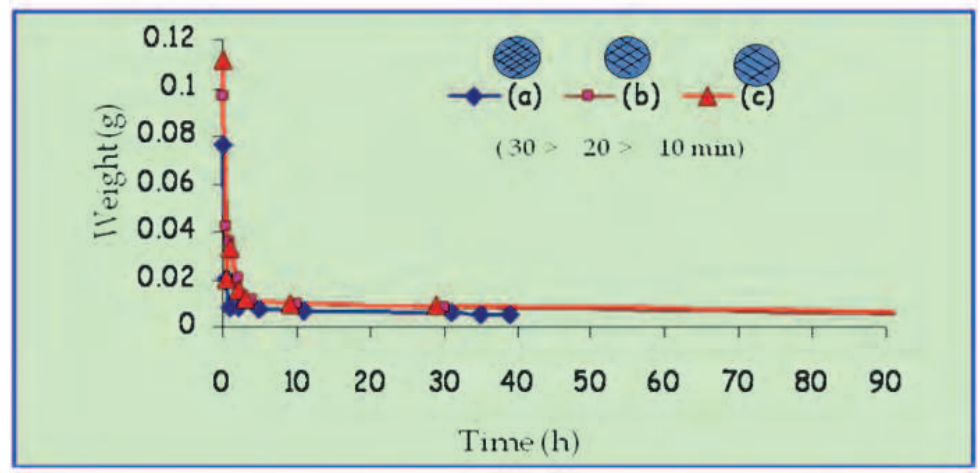

Fig. 13. Effect of crosslinking on drying of beads at different exposured times to GA solution (Riyajan \& Sakdapipanich, 2009a) 


\section{Coating of capsule with NR}

Concentrated NR latex used in this study is high ammonia latex received from Jana company, Co., Ltd. (Songkhla Thailand).

$\%$ TSC of latex is calculated from the percentage by weight of the concentrated latex which is non-volatile at a definite temperature in an open atmosphere. The \% TSC of concentrated NR latex in this study was determined by using method described in ASTM D107688 as shown in equation (1).

$$
\% \operatorname{TSC}=(W / W t) \times 100
$$

Where, $\mathrm{W}=$ weight of dry NR sample $(\mathrm{g})$

$\mathrm{Wt}=$ weight of NR latex sample $(\mathrm{g})$

$\% \mathrm{DRC}$ of latex is defined as the percentage by weight of the concentrated latex which is precipitated by acetic acid. The \% DRC of concentrated NR latex was determined (equation 2) by using method described in ASTM D1076-88.

$$
\% D R C=\left(W_{x} / W_{t}\right) \times 100
$$

Where, $W_{x}=$ weight of dry NR coagulum $(g)$

$\mathrm{W}_{\mathrm{t}}=$ weight of NR latex sample $(\mathrm{g})$

The $5 \mathrm{~g}$ of dried NR were dissolved in toluene $(50 \mathrm{ml})$ in beaker $(250 \mathrm{ml})$. The capsules $(5 \mathrm{~g})$ were dipped to the toluene solution and dried at room temperature.

So, the dry capsules of crosslinked sodium alginate mixed with neem Aza-A (7000 ppm) were dipped into a toluene solution of NR $(5 \% \mathrm{w} / \mathrm{w})$.Then, the coating capsules were dried at $30^{\circ} \mathrm{C}$ for $24 \mathrm{~h}$. Multiple coatings were prepared by the immersion of the single-coated neem capsules into a NR with $30 \%$ DRC. Thereafter, the procedure was the same as during the preparation of single-coated neem capsules. The third-coated neem capsules were derived by the dipping of double-coated neem capsules into a NR with 30\%DRC and then the same methodology as that given above mention. Fourth-coatings were prepared by the immersion of the third-coated neem capsules into a NR with $60 \mathrm{DRC}$ and dried at $60^{\circ} \mathrm{C}$ until its weight was constant.

\section{ii. Spray dryer method}

In a number of processes, a core material is imbedded in a polymeric matrix during formation of the particles. A simple method of this type is spray-drying, in which the particle is formed by evaporation of the solvent from the matrix material. However, the solidification of the matrix also can be caused by a chemical change. The ratios of polymer with $0,40 \%$ and $87 \%$ hydrolyzed polyvinyl acetate (PVAc) and distilled water containing glutaraldehyde $5 \% \mathrm{w} / \mathrm{v}$ and $0.1 \%$ hydrochloric acid, given in Table 1, were prepared for the encapsulation of the neem Aza-A product. Suitable amounts of the neem Aza-A product in solution were added to the polymer solutions in water to obtain mixtures of the neem AzaA solution: polymer in the proportion of 10:5 (w/w). Microcapsules were obtained by spraying the solutions through a mini spray dryer Buchi-191 equipped with a $0.7 \mathrm{~mm}$ nozzle at $206 \mathrm{kPa}$. The microparticles were collected and stored under vacuum at room temperature for $48 \mathrm{~h}$. Fig. 14 shows the procedure of preparing capsule neem obtained from spray dryer. 


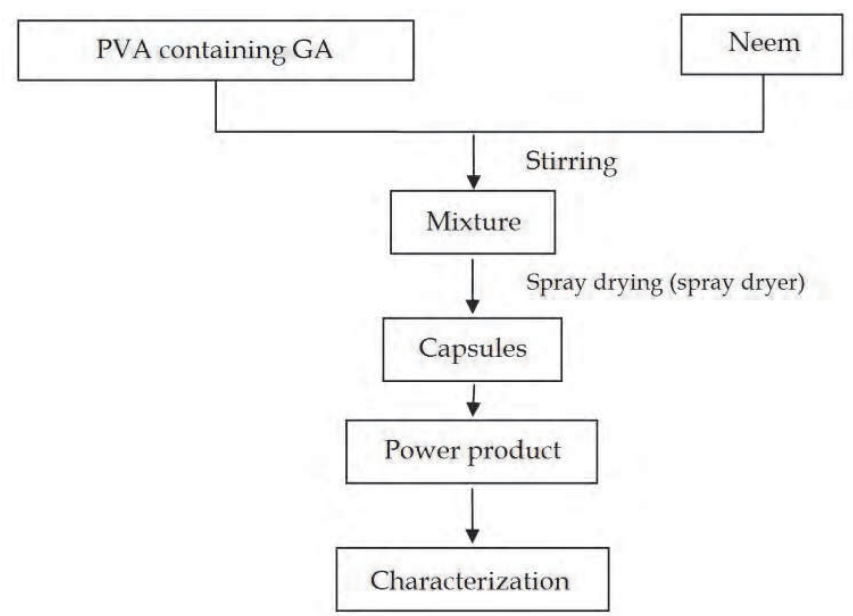

Fig. 14. Procedure of preparing neem Aza-A capsule obtained from spray dryer

\section{Characterization of capsule}

Particle size and morphology of capsule

Five samples of the completely dried beads from different formulations were selected and their sizes were measured by using a micrometer screw gauge (Sargent, USA) with an accuracy of $\pm 0.01 \mathrm{~mm}$ for capsule obtained from coaservation. Capsules were prepared using sodium alginate and PVA solutions at $5 \%(\mathrm{w} / \mathrm{v})$ concentration. The average diameter of the capsules ranged from 1.2 to $1.4 \mathrm{~mm}$. The particles produced in this work were analyzed for their sizes using the light scattering method. The SEM photographs of capsule were shown in Fig. 15 and it is clear that the particles are egg in shape. The mean particle size was $0.14 \mathrm{~mm}$ observed by both OM and SEM. After the capsules were coated with NR, their diameter was drastically increased from $0.14 \mathrm{~mm}$ to be $3 \mathrm{~mm}$ and more smooth on surface of capsule was also observed. In case of spray dryer, the average of particle size of capsule was roughly 50 micron (Riyajan \& Sakdapipanich, 2009b). In addition, the shape of this capsule depend on the blend ratio between PVA and sodium alginate, in which it change from spherical to egg-like due to the different viscosity of the mixture between PVA and sodium alginate (Riyajan \& Sakdapipanich, 2010). The surface of the capsule was investigated by many techniques such as electron probe microanalysis, atomic force microscopy and SEM and detail was displayed in (Riyajan \& Sakdapipanich, 2010).

Swelling study of the individual beads

Swelling property of the beads was subjected to a measurement of swelling ratio in aqueous medium as a function of time. The bead samples exposed to GA at different time were selected and incubated with distilled water in a watch glass. The mass of all bead samples was taken at different interval period times and the average value was calculated. During this process, care should be exercised while it was handed of the swollen beads so as to avoid any weight loss due to breaking or erosion of the beads. All the mass measurements of the swollen beads were taken on a Mettler single pan balance and having accuracy up to fifth decimal. The percentage swelling ratio of bead was calculated as in equation 3 . 


$$
\% \text { Swelling ratio }=\frac{\left(W_{1}-W_{2}\right)}{W_{1}} \times 100
$$

Where, $W_{1}$ and $W_{2}$ are wet weight and dried weight, respectively.

(a)

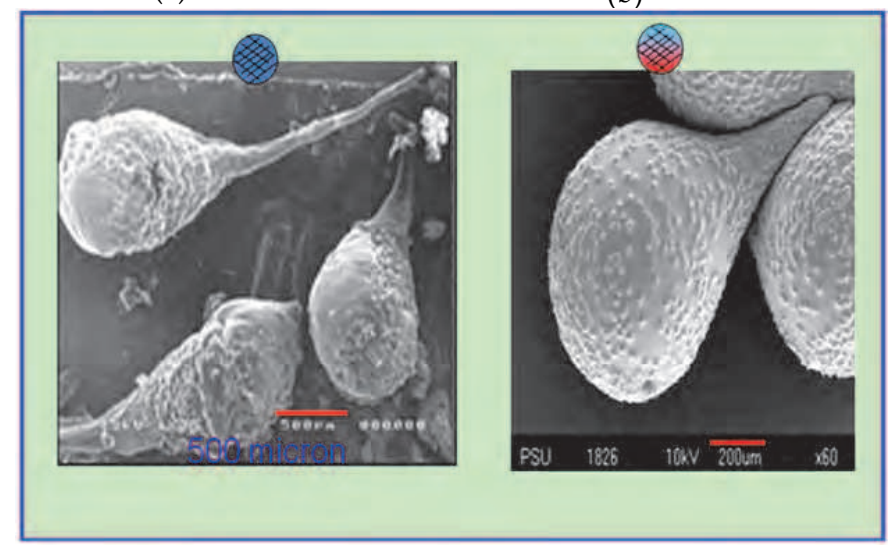

Fig. 15. Scanning electron microscopic photographs of capsule beads (a) sodium alginate and (b) sodium alginate: PVA (75:25) (Riyajan \& Sakdapipanich, 2009a).

\begin{tabular}{ccc}
\hline $\begin{array}{c}\text { Ratio between polymer } \\
\text { and distilled water }\end{array}$ & $\begin{array}{c}\text { \% Efficiency of } \\
\text { yield (\%S.D) }\end{array}$ & $\begin{array}{c}\text { \% Efficiency of } \\
\text { encapsulation (\%S.D) }\end{array}$ \\
\hline $\begin{array}{c}\text { 0\% Hydrolyzed PVAc: distilled } \\
\text { water }\end{array}$ & & \\
$1: 20$ & $85(2)$ & $75(4)$ \\
$1: 35$ & $95(2)$ & $78(4)$ \\
$1: 40$ & $96(2)$ & $79(2)$ \\
water & & \\
$1: 20$ & & $76(2)$ \\
$1: 35$ & $86(3)$ & $78(2)$ \\
$1: 40$ & $94(3)$ & $80(3)$ \\
40\% Hydrolyzed PVAc distilled & $96(3)$ & \\
water & & $79(3)$ \\
$1: 20$ & & $80(5)$ \\
$1: 35$ & $84(4)$ & $81(2)$ \\
\hline
\end{tabular}

Table 1. Efficiency of yield and efficiency of encapsulation obtained at different ratios between polymer and distilled water (Riyajan \& Sakdapipanich ; 2009) 
The swelling of any capsule in a aqueous medium depends on crosslinking density (Riyajan \& Sakdapipanich, 2009a), polymer blend ratio (Riyajan \& Sakdapipanich 2010), NR coating layer (Riyajan \& Sakdapipanich, 2009), and \% hydrolysis of PVAc (Riyajan \& Sakdapipanich, 2009b) as well as crystalline region(Riyajan \& Sakdapipanich, 2010).

Fig. 16 reveals the effect of crosslinking on percentage of swelling ratio by beads at various exposure times to GA. It was found that all the beads show a maximum amount of water absorption during the first hour, but beads formed by exposing for only $10 \mathrm{~min}$ to the crosslinking agent absorb more water than the beads formed by exposing for 20 and $30 \mathrm{~min}$. The particles produced in this work were analyzed for their sizes using the light scattering method. NeemAza-A release from the beads were subjected to a number of physical and chemical parameters including those related directly to the release medium, the release conditions (temperature) and those resulting from change in the characteristics of the controlling release device (beads).

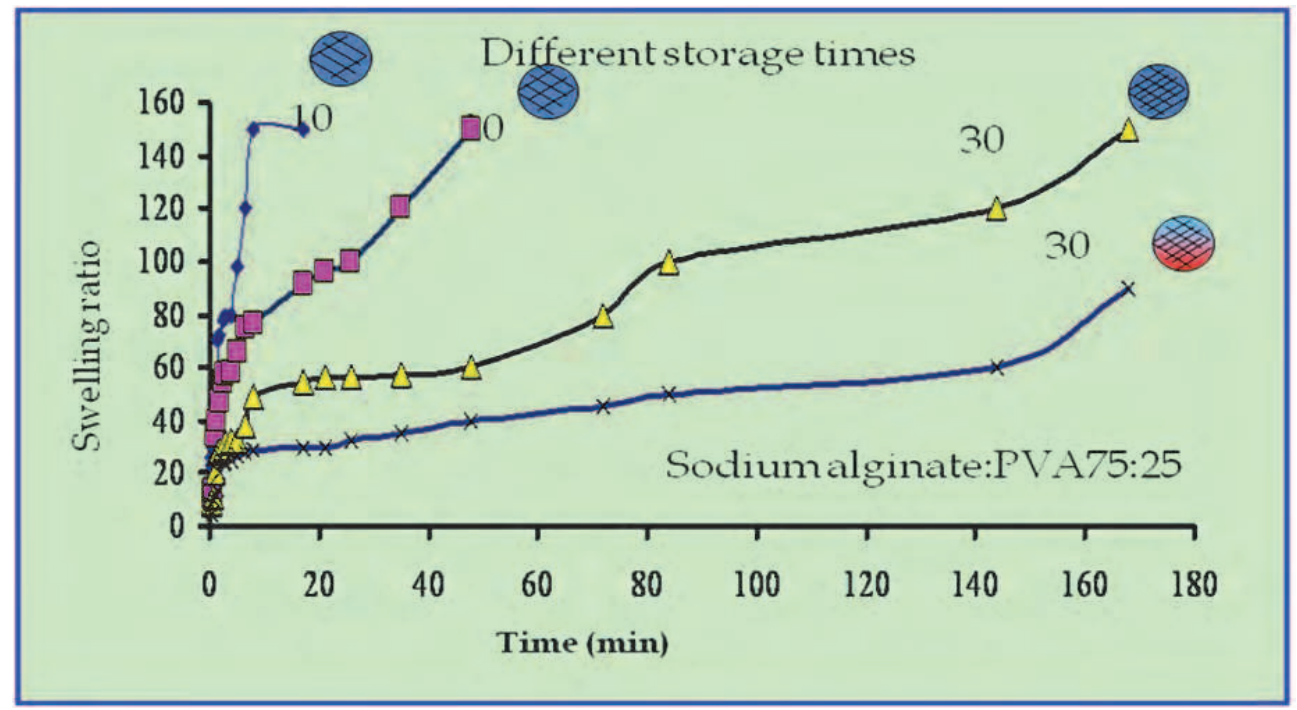

Fig. 16. Effect of crosslinking on percentage of water uptake by beads obtained from sodium alginate and sodium alginate/ PVA (75:25) (Riyajan \& Sakdapipanich, 2010)

Fig. 17 exhibit the effect of NR layer on percentage of swelling by beads prepared at $30 \mathrm{~min}$ storage time of GA solution. From the results reported in section, it can be said that the structure of capsules with influence the release rate of neem Aza-A should be improved by coating the capsule with NR. Diffusion in polymers is an important mechanism in pharmacy for the controlled release of drugs (Vanderaer, 1974). Diffusion in polymeric systems is passive, if the driving force is purely a brownian molecular motion, but diffusion can also be activated by external effects, either by the influence of the release medium by swelling or biodegradation, or by the effects of physical forces as electrical, osmotic or convective forces. The fundamental of diffusion is based on Fick's laws which describe the macroscopic transport of molecules by a concentration gradient (Vanderaer, 1974).

The suitable coating material must be nonreactive, essentially immiscible with the material being encapsulated and capable of being rapidly hardened to form a film. NR was selected to 
be a coating agent of neem Aza A-sodium alginate capsules to provide an adequate barrier wall. So, the dry capsules of crosslinked sodium alginate mixed with neem Aza-A (7000 ppm) were dipped into a toluene solution of NR $(5 \% \mathrm{w} / \mathrm{w})$. Then, the coating capsules were dried at $30^{\circ} \mathrm{C}$ for $24 \mathrm{~h}$. Multiple coatings were prepared by the immersion of the single-coated neem Aza-A capsules into a NR with 30 DRC. Thereafter, the procedure was the same as during the preparation of single-coated neem Aza-A capsules. The third-coated neem Aza-A capsules were derived by the dipping of double-coated neem Aza-A capsules into a NR with $30 \%$ DRC and then the same methodology as that given above mention. Fourth-coatings were prepared by the immersion of the third-coated neem Aza-A capsules into a NR with $30 \%$ DRC and dried at $60^{\circ} \mathrm{C}$ until its weight was constant. It is clear that the rate of swelling decreased dramatically after coating neem Aza-A capsule with NR compared with that of the bead without coating. When NR layer on capsules increased, the swelling ratio of these resulting capsules dramatically decreased, especially capsule bead obtained from three-coated NR. The swelling ratio of neem Aza-A obtained from first-coated neem Aza-A in aqueous medium at 2, 24, 72 and $240 \mathrm{~h}$ of storage neem Aza-A was 10, 29, 38 and 60\%, respectively. When the NR-coated on capsules increased from 1 to be 3 layers, the swelling ratio of neem Aza-A obtained from firstcoated neem Aza-A in aqueous medium at 2, 24, 72 and $240 \mathrm{~h}$ of storage neem Aza-A was 2, 5, 5 and $30 \%$, respectively.

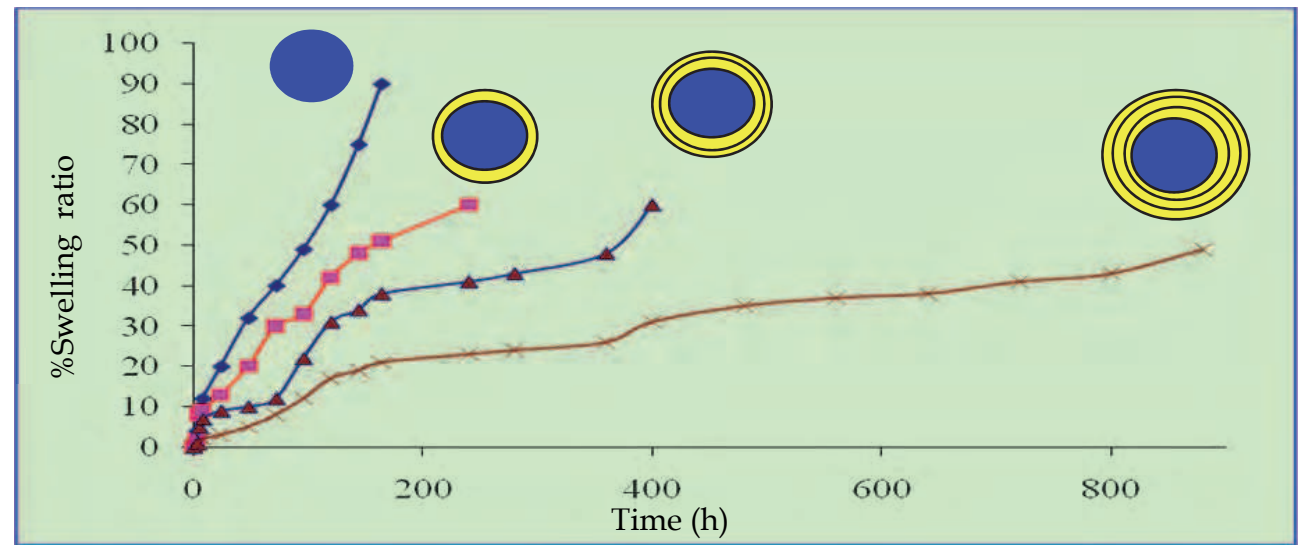

Fig. 17. Effect of NR on percentage of water uptake by beads obtained from sodium alginate and sodium alginate/ PVA (75:25) (Riyajan \& Sakdapipanich, 2009a)

\section{Interaction of capsule and neem}

Fourier transforms infrared; FTIR and XRD data were obtained to detect any chemical interactions between neem and sodium alginate and sodium alginate alone. The possible reaction between sodium alginate and GA in presence of hydrochloric acid is presented in Fig. 18. The presence of a large number of hydroxyl groups in PVA resulting from semiinterpenetration between sodium alginate and PVA and strong hydrogen bonding will affect the solubility of PVA in aqueous medium. The changes of the characteristic spectra peaks reflect the chemical interactions when two or more substances are blended (Riyajan \& Sakdapipanich, 2010). After adding GA to blend samples, the intensity of the diffraction peak at 19o for PVA becomes flatter and broader (Riyajan \& Sakdapipanich, 2010). 


\section{Photodegradation and thermal studied}

Thermal studies were conducted with Mettler-Toledo instrument (TGA/SDTA 851) analysis the heating rate for the thermogravimetric analysis of sodium alginate alone and capsule beads was $30 \circ \mathrm{C} / \mathrm{min}$. A small amount $(1-3 \mathrm{mg}$ ) of sample was taken for the analysis and the samples heated from 30 to $800^{\circ} \mathrm{C}$ at in nitrogen. The TGA and DTG curves are drawn for each sample. The increase in NR layer on capsule was further confirmed by TGA analysis. The weight loss before $400^{\circ} \mathrm{C}$ in the TGA curves was attributed to the thermal degradation of polymer coating from capsules, from which the polymer content in the capsules particle. The TGA and derivative thermogravimetry (DTG) curves for the pyrolysis of capsules are shown in Fig.19. It was found that pure sodium alginate began to degage at $100^{\circ} \mathrm{C}$ and the residue left was about $0 \%$ at $450^{\circ} \mathrm{C}$ and reaches to maximum at $243^{\circ} \mathrm{C}$. The NR shows better thermal stability than that of sodium alginate alone. For neem Aza-A capsules, the degradation of neem Aza-A experienced a comparatively long time and wide temperature range until $450^{\circ} \mathrm{C}$. In the case of capsule NR coating, below $250^{\circ} \mathrm{C}$ there is no degradation. In the temperature range of $250-400^{\circ} \mathrm{C}$ about $85 \%$ of the material is degraded. During this stage weight loss and volatilization of degradation products take place rapidly. Beyond $420^{\circ} \mathrm{C}$ the weight loss is about $6-7 \%$. The weight loss contents of capsule with NR coating at from 320 to $450 \circ \mathrm{C}$ increased with NR coating layers on capsules.
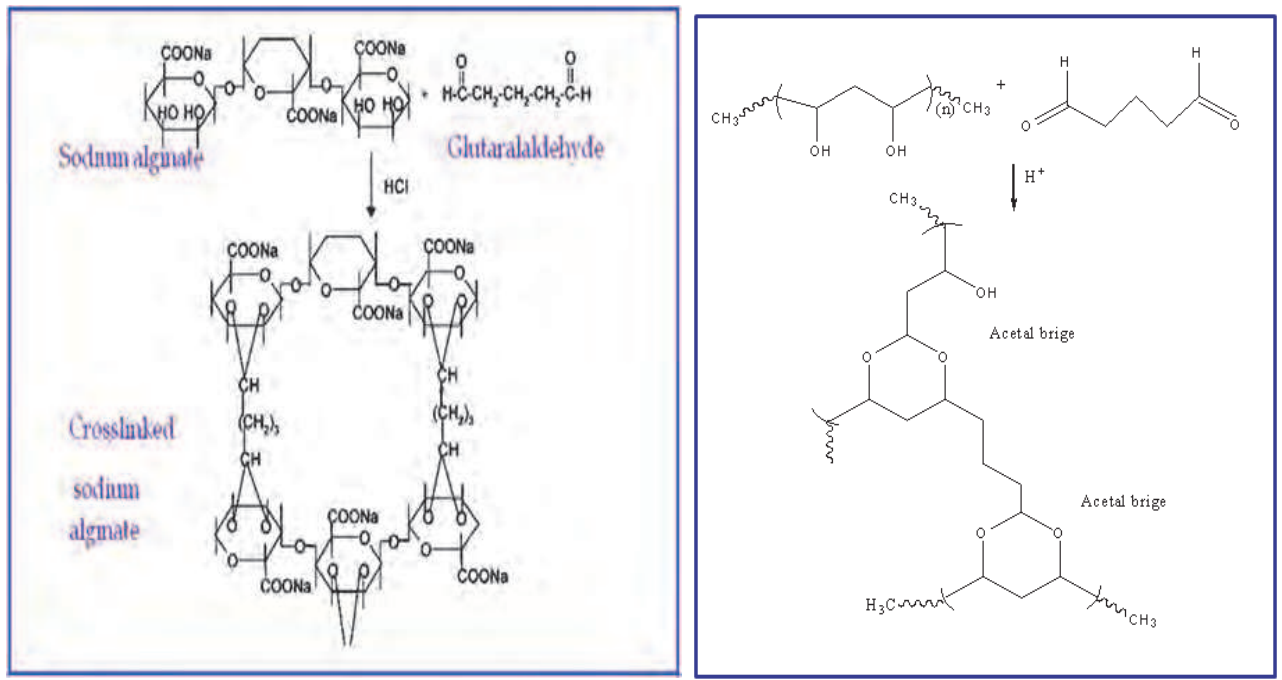

Fig. 18. The crosslinking product (a) between sodium alginate and GA containing acid and (b) between sodium alginate and GA containing acid (Riyajan \& Sakdapipanich, 2010)

The rate of neem Aza-A degradation was reduced rapidly from the time of initiation and became constant after $30 \mathrm{~h}$ of UV irradiation as shown in Fig.20. When the neem oil was irradiated for 10 and $30 \mathrm{~h}$, the residual neem Aza-A was 50 and 19\%, respectively. The results responds to (Sundaram, \& Curry, 1996). Based on the UV spectral data, UV protectants can be selected and matched to stabilize UV-labile pesticides. The employed material matrix for encapsulation of neem Aza-A was 0, 40, and 87\% hydrolyzed PVAc. These results show that the efficiency of thermal stability for encapsulated neem Aza-A 
obtained from the $87 \%$ hydrolyzed PVAc was higher than that of other samples. The residual of neem Aza-A for encapsulated neem Aza-A obtained from the non hydrolyzed PVAc was 85 and $78 \%$ after 10 and $30 \mathrm{~h}$ of UV irradiation time.

\section{Release content uniformity, dissolution and releasing studies}

Beads were evaluated for the neem content and this was done by refluxing a known mass of the beads with $100 \mathrm{ml}$ of methanol at $65^{\circ} \mathrm{C}$. Refluxing was continued for $1 \mathrm{~h}$ to ensure complete extraction of neem Aza-A from the beads. Then the absorbance of methanol containing the extracted amount of neem Aza-A was taken at a wavelength of $211 \mathrm{~nm}$ in a HPLC (PerkinElmer LC) using pure methanol as a blank.

II
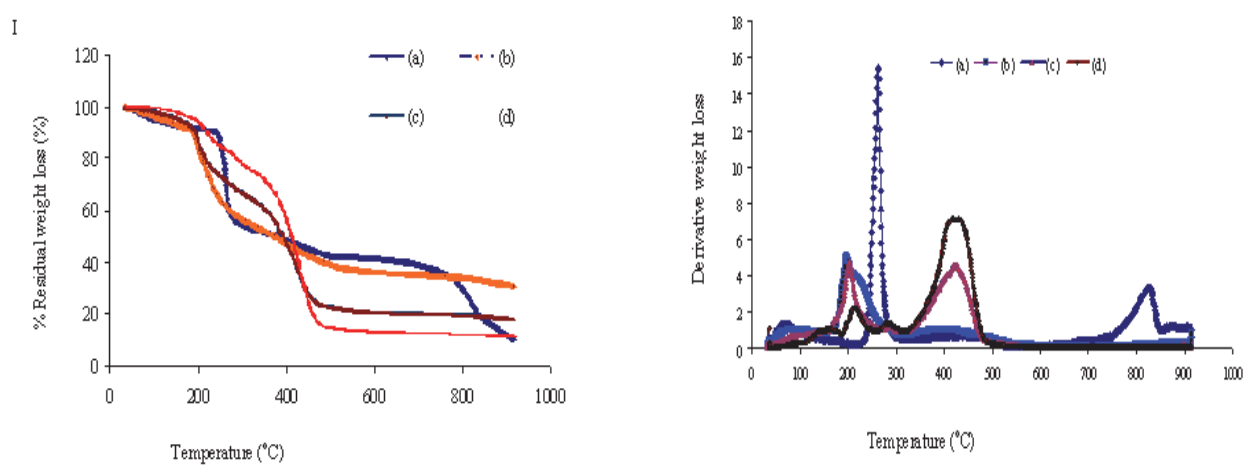

Fig. 19. Thermal behaviour of the capsule analyzed by I) TGA and II) DTG of sodium alginate alone (a) and capsules with (b) 0, (c) 1, (d) 2, and (c) 3 layers of NR coating

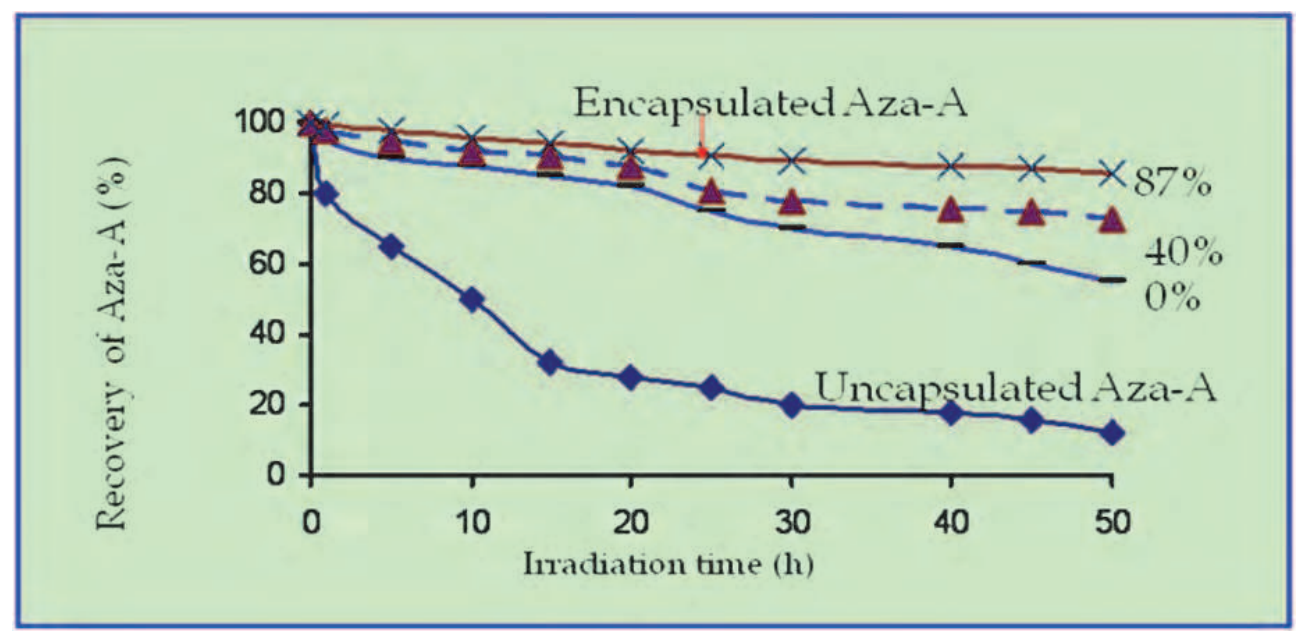

Fig. 20. Photodegradation behaviour of the capsule under UV irradiation (Riyajan \& Sakdapipanich, 2009b) 
The dissolution study was done in 250-ml conical flasks containing the dissolution media ( $0.1 \%$ Tween-80 solution in distilled water) with the closer caps which were kept in an incubator (WTB Binder, Germany) maintained at $35^{\circ} \mathrm{C}$ as shown in Fig.21. Two to three beads weighing about $10 \mathrm{mg}$ were taken in the dissolution media. At definite intervals of time, the conical flasks were shaken well and a 10-ml aliquot was taken for the analysis of neem Aza-A using HPLC (PerkinElmer LC) at $211 \mathrm{~nm}$. Experiments were performed in triplicate in order to minimize the variation error. The cumulatively release of neem Aza-A from capsule beads was estimated from HPLC experimental.
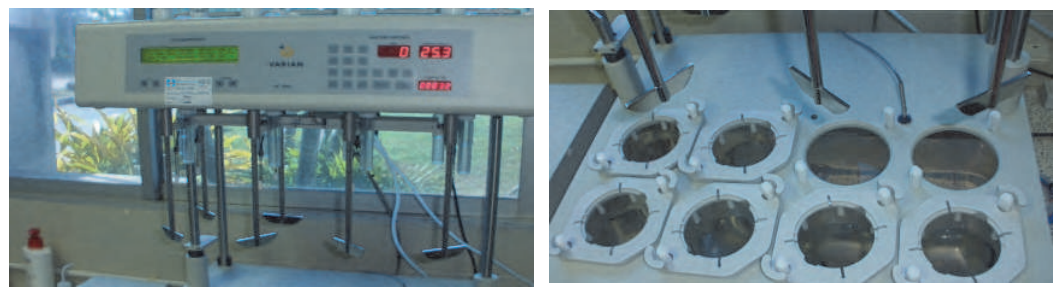

Fig. 21. Photographs of dissolution equipment from digital camera

Coaservation (Riyajan \& Sakdapipanich, 2009a)

The encapsulation of neem (as called capsule) was prepared by sodium alginate as a controlled release polymer after crosslinking with GA, and then the capsule was coated with NR solution. The optimum condition for encapsulation of neem such as storage time in GA solution was investigated. In order to optimize the drying conditions, some samples of the beads with different extent of crosslinking were selected such that the initial weight is nearly equal. The percentage entrapment efficiency was varied by varying exposure time periods to the crosslinking agent. It was found that the percentage entrapment efficiency decreased drastically with a decrease in aqueous medium. Beads produced in $5.0 \% \mathrm{HCl}$ in methanol exposed for $10 \mathrm{~min}$ showed the highest entrapment efficiency i.e., 91.2\% and the lowest entrapment efficiency i.e., $73.6 \%$ was observed for $0.5 \% \mathrm{HCl}$ content in methanol exposed for $30 \mathrm{~min}$. Neem Aza-A is soluble in aqueous media and hence, an increase in the percentage entrapment efficiency was observed with an decreasing storage time period in GA containing $\mathrm{HCl}$ as a catalyst due to the increased release of the neem Aza-A from the matrix at longer time of exposure. Neem Aza-A release from the beads were subjected to a number of physical and chemical parameters including those related directly to the release medium, the release conditions (temperature) and those resulting from change in the characteristics of the controlling release device (beads). The effect of degree of crosslinking of sodium alginate beads on the kinetics of neem Aza-A release is depicted in Fig. 22. It is found that the higher the exposure time to GA the higher the release rate. The release rate of neem Aza-A beads at 10 min with exposure to GA have shown $100 \%$ release in the $5 \mathrm{~h}$, whereas the neem Aza-Aloaded beads with exposure to GA have shown $100 \%$ at $10 \mathrm{~h}$, but neem Aza-A-loaded beads with exposure to GAe have shown $100 \%$ release at $25 \mathrm{~h}$. To observe the effect of the extent of crosslinking on the release kinetics of the beads exposed to the crosslinking agent, exposure to GA at 30 min were selected for NR coating. The effect of release rate of neem Aza-A from the beads coated with different layers of NR and exposed for $30 \mathrm{~min}$ to GA are presented in Fig. 23. The release profile from neem Aza-A without NR coating is also shown for comparison. It is obvious that the neem Aza-A release rate is reduced significantly by NR coating, which is consistent with the results of the swelling study. The NR film is very strong, rigid and hard to 
swell, so the diffusion through this coating is the rate limiting step for swelling and neem AzaA release. The release was prolonged by additional natural rubber layers on the capsule surface. The neem Aza-A cumulatively release of capsule derived from 2, 24, 72 and 240 in aqueous medium was 31,69, 81 and 100\%, respectively and when NR coated on capsule increase from 1 to be 3 layers, the neem Aza-A cumulatively release of capsule stored in at the same condition was $8,29,36$ and $60 \%$, respectively.

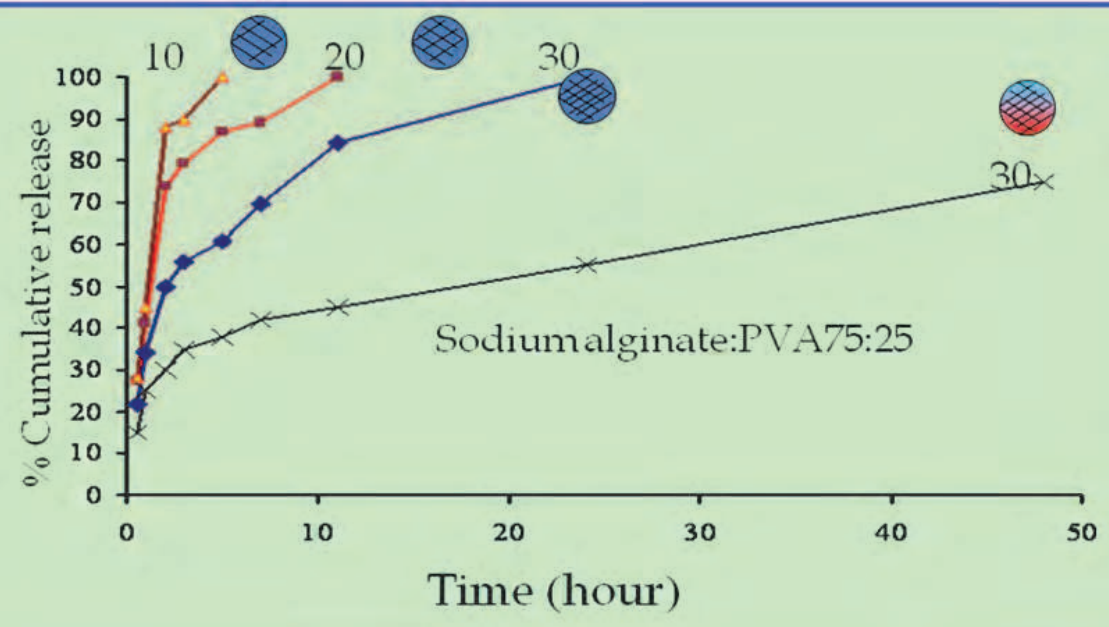

Fig. 22. Effect of crosslinking on releasing neem Aza-A for beads obtained from sodium alginate with different times and sodium alginate/PVA (75:25)

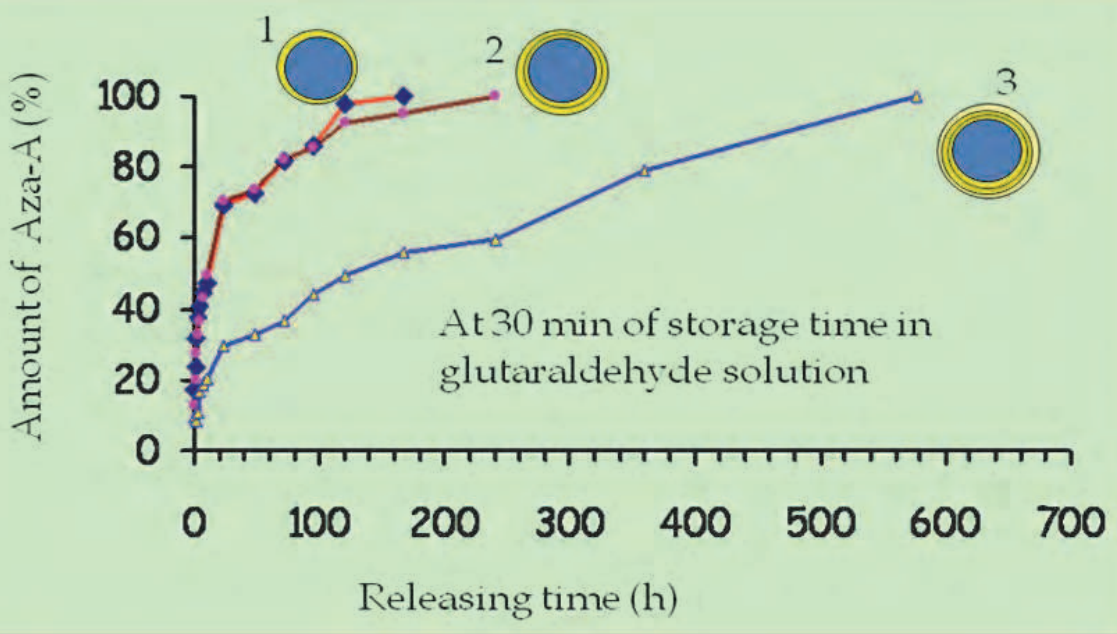

Fig. 23. Effect of crosslinking on the release neem for capsules coated NR (a) 1 layer (b) 2 layers and (3) 3 layers of NR (Riyajan \& Sakdapipanich, 2009a) 
It is to be noted that with an increase in NR coating, the capsule matrix becomes more dense resulting in a decrease in the rate of diffusion of neem Aza-A through the swollen beads, especially beads with three- NR.

Spray dryer (Riyajan \& Sakdapipanich, 2009b)

The neem Aza-A was dispersed evenly throughout the matrix of the capsule and was unable to diffuse to any significant extent within the matrix. However when the polymer matrix was placed in a thermodynamically compatible medium, the hydrolyzed PVAc swelled owing to absorption of the medium, then the neem Aza-A in the swollen part diffused out of the polymer matrix. The release of the neem Aza-A from the polymer matrix has been schematically described in Fig. 24.

Results of a study of the effect of polymer types on its rate of release in distilled water from capsules with 0, 40 and 87\% hydrolyzed PVAc is shown in Fig. 24 and Table 1. It is clear that the release rate of neem Aza-A from the microcapsules was proportional to the release time. The release rate of neem Aza-A from microcapsules obtained from non hydrolyzed PVAc was high during the first $10 \mathrm{~h}$ followed by a slow release. Release of neem Aza-A from the non hydrolyzed PVAc microcapsules was found to be almost complete within about $15 \mathrm{~h}$. This result indicates that high amount of neem Aza-A was presented on its surface of capsules. In the case of capsules obtained from the 40 and $87 \%$ hydrolyzed PVAc, the release rate of neem Aza-A from the microcapsules was high during the first $15 \mathrm{~h}$. followed by a slow release. Finally, release of neem Aza-A from the microcapsules obtained from $40 \%$ and $87 \%$ hydrolyzed PVAc was found to be almost complete within about 25 and $30 \mathrm{~h}$, respectively. This result indicates that neem Aza-A was entrapped in the polymer matrix. This could be explained by the amount of neem Aza-A released being dependent on its hydrophilicity in the polymer matrix as well as its solubility in water.

\section{Mechanism}

The release results were investigated by using an empirical equation to estimate the value of $\mathrm{n}$ as follows (equation 4).

$$
M_{t} / M_{\infty}=K t^{n} \text { or } \log \left(M_{t} / M_{\infty}\right)=\log (K)+n \log (t)
$$

Where $M_{t} / M_{\infty}$ is the released fraction at time $t, n$ is the release exponent, and $K$ is the release factor. From the slope and intercept of the plot of $\log \left(M_{t} / M_{\infty}\right)$ against $\log (t)$, kinetic parameters $n$ was calculated as shown in Fig 25.

The $\mathrm{n}$ value of neem Aza-A coated with NR is represented, estimated from Fig.25. It was found that the $\mathrm{n}$ value of this sample obtained from $0,1,2$ and 3 layers was $0.3515,0.3766$, 0.4476 and 0.3497 , respectively at regression of $0.9988,0.9875,0.9870$ and 0.9991 , respectively. Thus, the neem Aza-A release mechanism of beaded coated with NR was Fickian diffusion. From previous works, on the basis of the diffusion exponent, an $\mathrm{n}$ value of 0.5 indicates that the release mechanism approaches a Fickian diffusion controlled release, whereas when $\mathrm{n}$ is equal to 1.0 this indicates the release mechanism approaches a zero-order release. In addition, an $\mathrm{n}$ value from 0.5 to 1.0 indicates a reactive agent release meachanism for non-Fickian diffusion (Riyajan \& Sakdapipanich, 2010). Authours found that the value of $n$ of 0.33 for the sample obtained from 75/25 PVA/sodium alginate after 30 min storage time in GA solution indicates that the release in this system deviates from a Fickian diffusion controlled release(Riyajan \& Sakdapipanich, 2010). 


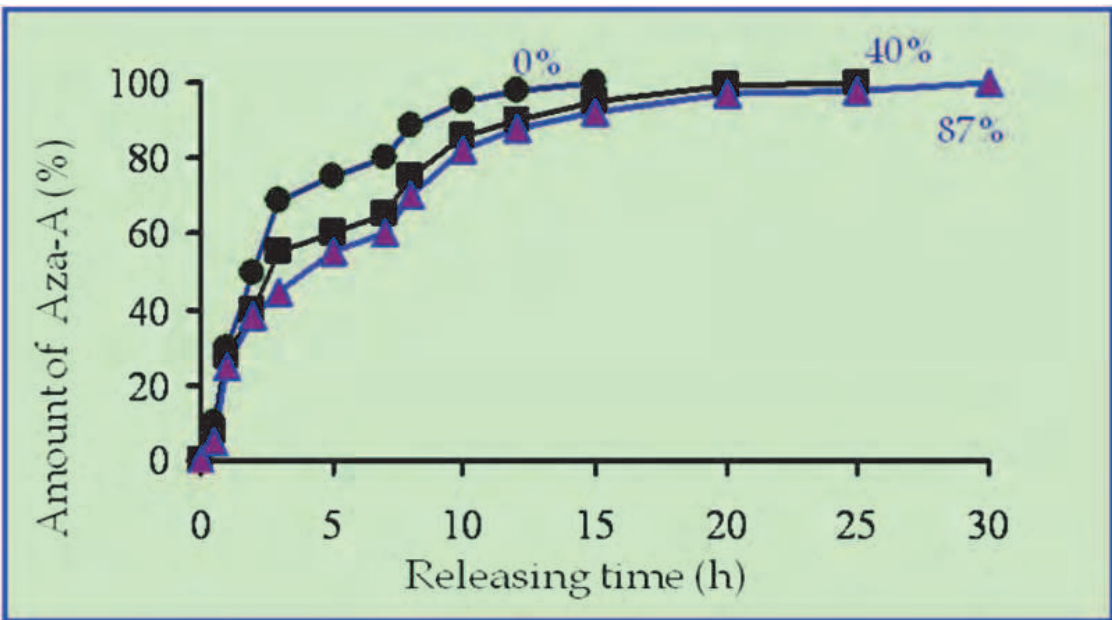

Fig. 24. Relationship between release rate of neem Aza-A and release time from microcapsules derived from encapsulated neem Aza-A in different hydrolyzed PVAc containing GA (Riyajan \& Sakdapipanich, 2009b)

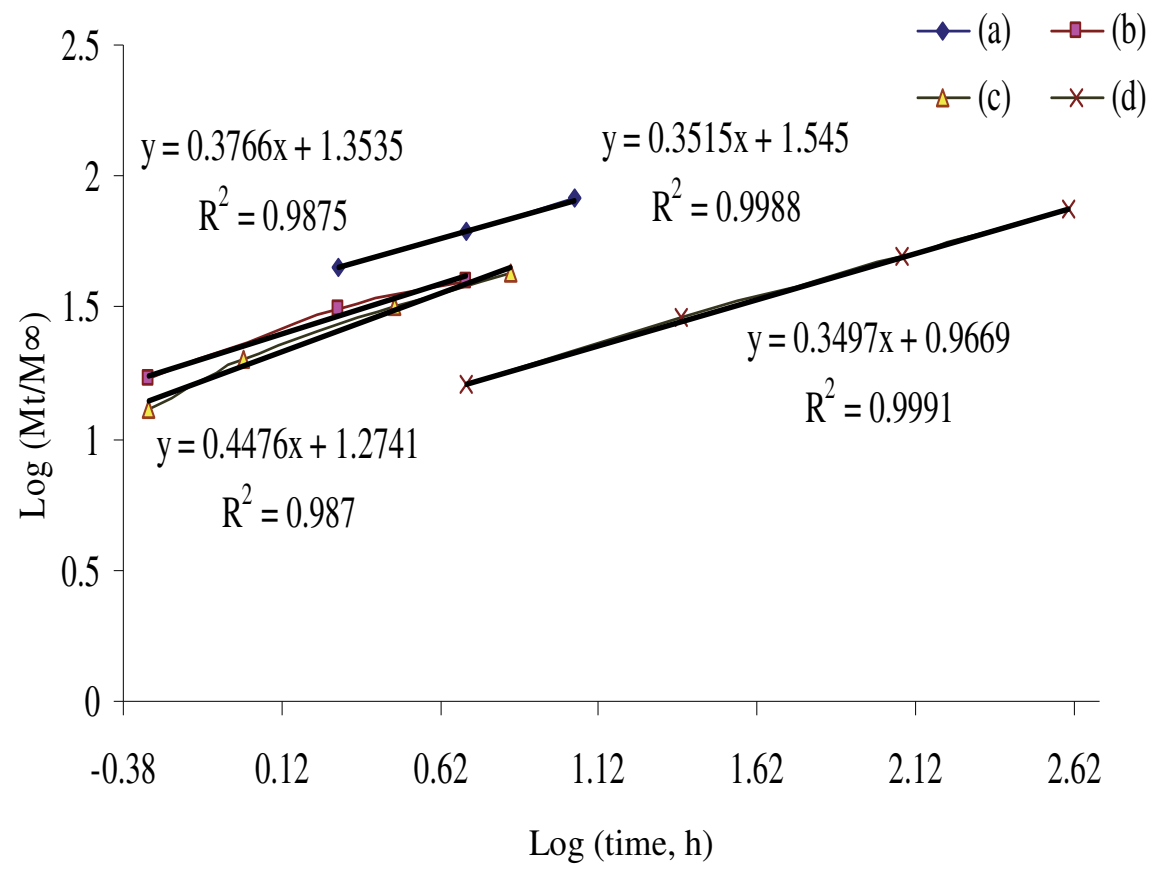

Fig. 25. Kinetic behaviour of the capsule with uncoated NR (a) and coated with (b) 1, (c) 2 and (d) 3 layer (s) of NR (Riyajan \& Sakdapipanich, 2009a) 
The representation of swelling type controlled release system of neem Aza-A in aqueous medium is presented in Fig.26. The neem Aza-A from capsule coated with NR may be released by swelling process under particular conditions. In other systems, the wall is swollen by water action (Riyajan \& Sakdapipanich, 2009a). In parallel, there are cases where the polymer matrix shows swelling with no significant limitations. The many factors affecting on the rate of the diffusion transfer of a solvent, including (a) the polymer transition from glassy to rubberlike state; (b) relaxation transitions on the surface and in the bulk of a sample; (c) dependence of the diffusion mobility of water on its concentration in the polymer; (d) expansion of the sample, reaching several tens or even a few hundred percentages with respect to the initial dimensions, requires development of a complicated multiparametric model of the water transport in polymers. In addition, the rate of neem Aza-A from capsule depend on NR coating. Thus, the time required to neem Aza-A from capsule increased with increasing NR coating layers.

In further work, all countries concentrate to the increasing concern globally regarding food production due to the exponentially increased human population by no changing environment. Therefore, the agriculture researchers find new pesticide herb and develop the method of encapsulation of herb with biopolymer. From previous work, the rapid increase in the number of publications was observed by the ISI Web of Knowledge concerning about "herbicide(s) or fungicide(s) or insectides(s)" and "metabolomics" or "metabonomics" or "metabolic fingerprinting" or "metabolic profiling" over the last decade (Aliferis, 2011). In addition, the particle size of capsule will be reduced to nano size. In parallel, the equipment of preparing capsule would be also developed.
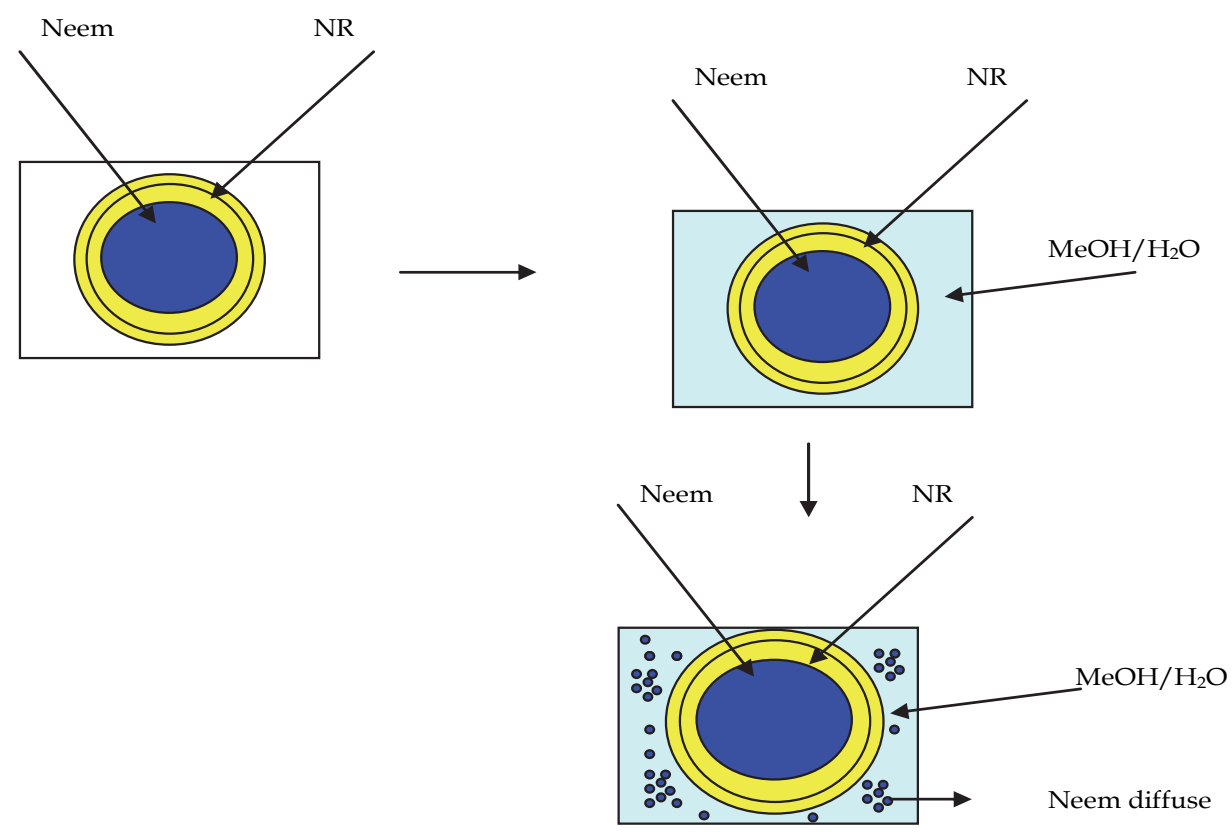

Fig. 26. Schematic representation of swelling type controlled release system of neem containing capsule dispersed in matrix Aza-A in aqueous medium 


\section{Conclusion}

The neem Aza-A can be successfully encapsulated into biopolymer like sodium-alginate , PVA and PVA/sodium alginate containing GA and then it was coated with NR matrix. The two approaches of the encapsulated neem Aza A were investigated. In the case of the first method, the microcapsules of neem Aza-A with partially hydrolyzed vinyl acetate with 0,40 and $87 \%$ hydrolysis as a matrix has also been prepared by spray techniques. Optimum condition of encapsulation for neem Aza-A by using spray drying was investigated. The SEM data indicated that the structure of the walls the beads are smooth and nonporous. The swelling results indicated that swelling of the polymeric beads decreases with increasing exposure time to the crosslinking agent. At particular intervals, the remaining concentration of neem Aza-A was analyzed by HPLC. The release data have been fitted to an empirical equation to estimate the kinetic parameter. It was found from the experiment that the ratio of $87 \%$ hydrolyzed poly (vinyl acetate) to water being 1:40 gave the highest concentration of neem Aza-A in the device. Finally, the successful encapsulation of neem Aza-A, was used by coaseversion technique and then coating with NR form. The swelling results indicated that swelling of the polymeric beads decreased with increasing exposure time to GA and reduced the rate of release of the pesticide. The degree of release of neem Aza-A from capsules was controlled by their condition of formation. In addition, we studied the effect of PVA/sodium alginate ratio on release of neem Aza-A from capsule. The degree of neem Aza-A release from capsule dramatically decreased when amount of PVA in composite blend increased. Inclusion, the obtained capsules have possible potential used in agriculture field.

\section{Acknowledgment}

The authors thank department of Materials science and technology, Prince of Songkla University for the use laboratory space. This study was supported by The Thailand Research Fund (MRG5080406).

\section{References}

URL:http:/ /www.bt.ucsd.edu/synthetic_pesticide.html, 2008

Aliferis, K.A., Chrysayi-Tokousbalides, M. Metabolomics, (2011).Metabolomics in pesticide research and development: review and future perspectives, Metabolomics Vol. 17 pp. 35-53.

Adoor, S.G., Manjeshwar, L.S., Bhat, S.D. \& Aminabhavi,T.M. (2008). Aluminum-rich zeolite beta incorporated sodium alginate mixed matrix membranes for pervaporation dehydration and esterification of ethanol and acetic acid, Journal of Membrane Science Vol 318 (No.1-2) pp.233-246.

Baker R.W. (2000). Medical Applications of Membranes,1st Editor, Membrane Technology and Applications, Mcgraw-Hill, New York,pp.443-467.

Burt, H.M., Jackson, J.K., Bains, S.K., Liggins, R.T., Oktaba, A.M.C. \& Arsenault, L.A. (1995). Controlled delivery of taxol from microspheres composed of a blend of ethylenevinyl acetate copolymer and poly (d,l-lactic acid), Cancer Letters Vol 88 (No.1) pp. 73-79. 
Chen, J.H., Liu, Q.L., Xiong, Y., Zhang ,Q.G. \& Zhu, A.M. (2008). Composite membranes prepared from glutaraldehyde cross-linked sulfonated cardo polyetherketone and its blends for the dehydration of acetic acid by pervaporation, Journal of Membrane Science Vol 325 No. 1 pp.184-191.

Devassine, M., Henry, F., Guerin, P. \& Briand X. (2002). Coating of fertilizers by degradable polymers, International Journal of Pharmaceutics Vol. 242 (No.1-2) pp. 399-404.

Dhumala, S.S.; Wagh, S.J.; Suresh A.k. (2008) Interfacial polycondensation-Modeling of kinetics and film properties Journal of Membrane Science Vol 325, No. 2, pp. 758-771.

Hunter, W.L. (1995) Controlled delivery of taxol from microspheres composed of a blend of ethylene-vinyl acetate copolymer and poly (d,l-lactic acid), Cancer Letter Vol 88 (No. 1) pp.73-79.

Fundueanu, G., Constantin, M., Bortolotti, F., Cortesi, R., Ascenzi, P. \& Menegatti, E. (2007). Cellulose acetate butyrate- $\mathrm{pH} /$ thermosensitive polymer microcapsules containing aminated poly(vinyl alcohol) microspheres for oral administration of DNA, European Journal of Pharmaceutics and Biopharmaceutics Vol 66 pp.11-16.

Guan, H., Chi, D., Yu, J. \& Li, X. (2008). A novel photodegradable insecticide: Preparation, characterization and properties evaluation of nano-Imidacloprid. Pesticide Biochemistry and Physiology Vol92 (No. 2):pp.83-91.

Hansena,T., Holmc, P. \& Schultza, K. (2004). Process characteristics and compaction of spray-dried emulsions containing a drug dissolved in lipid, International Journal of Pharmaceutics Vol 287 (No.1-2) pp. 55-66.

Ji, J., Childs, R.F., \& Mehta, M. (2001). Mathematical model for encapsulation by interfacial polymerization, Journal of Membrane Science Vol 192 (No.1-2) pp. 55-70.

Kim, D.J. \& Jung, J.Y. (2007). Granule performance of zirconia/alumina composite powders spray-dried using polyvinyl pyrrolidone binder, Journal of the European Ceramic Society Vol 27 (No.10) pp.3177-3182.

Leda Klouda, Kevin R. Perkins, Brendan M. Watson, Michael C. Hacker, Stephanie J. Bryant, Robert M. Raphael, F. Kurtis Kasper, Antonios G. Mikos (2011). Thermoresponsive, in situ cross-linkable hydrogels based on N-isopropylacrylamide: Fabrication, characterization and mesenchymal stem cell encapsulation Acta Biomaterialia, Vol 7, No. 4, pp. 1460-1467.

Liu, H.; Ye, H.; Zhang, Y.; Xinde Tang, X. (2008) Preparation and characterization of poly(trimethylolpropane triacrylate)/flaky aluminum composite particle by in situ polymerization, Dyes and Pigments, Vol 79 (No. 3) pp. 236-241.

Liu, H.,Ye, H.Q. \& Zhang Y.C. (2008) Preparation and characterization of PMMA/flaky aluminum composite particle in the presence of MPS, Colloids and Surfaces A: Physicochemical and Engineering Vol 315 No.1-3 pp. 1-6.

Kreutzweiser, D.P., Sutton, T.M., Back, R.C., Pangle, K.L. \& Thompson, D.G. (2004). Some ecological implications of a neem (azadirachtin) insecticide disturbance to zooplankton communities in forest pond enclosures, Aquatic Toxicology Vol67 (No. 3): pp. 239-254.

Kulkarni, A.R., Soppimath, K.S. \& Aminabhavi, T.M. (1999). Controlled release of diclofenac sodium from sodium alginate beads crosslinked with glutaraldehyde, Pharmaceutica Acta Helvetiae Vol 74 (No. 1) pp. 29-36. 
Kulkami, A.R., Soppimath, K.S., Aminabhavi, T.M., Mehta, M.H. \& Dave, A.M. (2001). Encapsulation efficiency and release kinetics of solid and liquid pesticides through urea formaldehyde crosslinked starch, guar gum, and starch + guar gum matrices, Journal of Applied Polymer Science Vol 82 (No. 11) pp2863-2866.

Kumbar, S.G., Kulkarni, A.R., Dave, A.M. \& Aminabhavi, T.M. (1999).Urea-formaldehyde crosslinked starch and guar gum matrixes for encapsulation of natural liquid pesticide [Azadirachta India A. Juss. (Neem) seed oil]: swelling and release kinetics. Journal of Applied Polymer Science Vol 73 (No.12) pp 2437-2446.

Mehyar, G.F., Liu, Z. \& Han, J.H. (2008). Dynamics of antimicrobial hydrogels in physiological saline, Carbohydrate Polymers Vol74 (No.1) pp.92-98.

Nazir Javed, S.R., Gowen, M., Inam-ul-Haq, K.A \& Shahina, F. (2007). Systemic and persistent effect of neem (Azadirachta indica) formulations against root-knot nematodes, Meloidogyne javanica and their storage life, Crop Protection Vol 26 (No.7) pp. 911-916.

Nochos, A., Douroumis, D. \& Bouropoulos, N. (2008). In vitro release of bovine serum albumin from alginate/HPMC hydrogel beads, Carbohydrate Polymers Vol 74 (No.

3) pp. 451-457.

Riyajan; S. \& Sakdapipanich, JT.(2009). Development of Neem Capsule Via Glutaraldehyde Crosslinked Sodium Alginate Capsules with Natural Rubber Coating its for its Control Release, Polymer bulletin Vol 63 (No. 4 ) pp.609-622.

Riyajan; S. \& Sakdapipanich, J.T. (2009). Encapsulated neem extract containing AzadiractinA within hydrolyzed poly(vinyl acetate) for controlling its release and photodegradation stability, Chemical Engineering Journal Vol 152 (No.2-3) pp.591597.

Riyajan, S. \& Sakdapipanich, J.T. (2010). Characterization of biodegradable semiinterpenetrating polymer based on poly (vinyl alcohol) and sodium alginate containing natural neem for its natural neem control release application, Polymer International Vol 59 (No. 8) pp.1130-1140.

Riyajan,S. \& Santipanusopon, S. (2010)Influence of ammonia concentration and storage period on properties field NR latex and skim coagulation, KGK-Kaustschuk Gummi Kunststoffe Vol 63(No.6) 240-244.

Rosenkranza, K., Kaspera, M.M., Wertherb J. \& Brunnera G. (2008). Encapsulation of irregularly shaped solid forms of proteins in a high-pressure fluidized bed, The Journal of Supercritical Fluids Vol 46 (No.3) pp. 351-357.

Ruan, G., Feng, S.S. \& Li, Q.T. (2002). Effects of material hydrophobicity on physical properties of polymeric microspheres formed by double emulsion process, Journal of Controlled Release Vol 84 (No. 3) pp. 151-160.

Sreenivasa, R.D., Davendra, K., Liza, J. \& Chandrasekaran, G.M. (2006). Granular formulation of neem seed extract and its process thereof, United State Patent No. 20060099233

Sundaram, K.M.S. \& Curry, J. (1996). Photostabilizers for Azadirachtin-A (A Nee m-Based Pesticide, Chemosphere Vol32 (No. 4) pp. 649-659. 
Sun, N., Wei, X., Wu, B., Chen, J., Lu, Y. \& Wu, W. (2008). Enhanced dissolution of silymarin/polyvinylpyrrolidone solid dispersion pellets prepared by a one-step fluid-bed coating technique, Powder Technology Vol 182 (No.1) pp 72-80.

Vanderaer, J.E. Microencapsulation (1974) Process and Applications; Plenum Press; New York and London, pp.3-4.

Veerapur, R.S., Gudasi, K.B. \& Aminabhavi, T.M. (2008). Sodium alginate-magnesium aluminum silicate mixed matrix membranes for pervaporation separation of water-isopropanol mixtures, Separation and Purification Technology Vol 59 (No. 2) pp .221-230.

Wei-Hong, T. \& Zhan-Qian, S. (2006). Research on Effect of Four Natural Ultraviolet Light Absorbers on Photostabilization of Azadirachtin-A. Agricultural Sciences in China Vol5 (No.11) pp.855-858.

Zhu, Z. \& Zhuo, R. (2001). Slow release behavior of starch-g-poly (vinyl alcohol) matrix for 2,4,5-trichlorophenoxyacetic acid herbicide, European Polymer Journal Vol37 pp.1913-1919. 


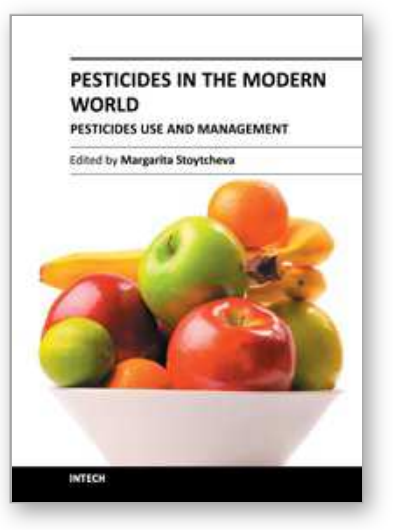

\author{
Pesticides in the Modern World - Pesticides Use and Management \\ Edited by Dr. Margarita Stoytcheva
}

ISBN 978-953-307-459-7

Hard cover, 520 pages

Publisher InTech

Published online 19, October, 2011

Published in print edition October, 2011

This book brings together issues on pesticides and biopesticides use with the related subjects of pesticides management and sustainable development. It contains 24 chapters organized in three sections. The first book section supplies an overview on the current use of pesticides, on the regulatory status, on the levels of contamination, on the pesticides management options, and on some techniques of pesticides application, reporting data collected from all over the world. Second section is devoted to the advances in the evolving field of biopesticides, providing actual information on the regulation of the plant protection products from natural origin in the European Union. It reports data associated with the application of neem pesticides, wood pyrolysis liquids and bacillus-based products. The third book section covers various aspects of pesticides management practices in concert with pesticides degradation and contaminated sites remediation technologies, supporting the environmental sustainability.

\title{
How to reference
}

In order to correctly reference this scholarly work, feel free to copy and paste the following:

Sa-Ad Riyajan (2011). Development of Neem Capsule via Biopolymer and Natural Rubber for Its Controlled Release, Pesticides in the Modern World - Pesticides Use and Management, Dr. Margarita Stoytcheva (Ed.), ISBN: 978-953-307-459-7, InTech, Available from: http://www.intechopen.com/books/pesticides-in-themodern-world-pesticides-use-and-management/development-of-neem-capsule-via-biopolymer-and-naturalrubber-for-its-controlled-release

\section{INTECH}

open science | open minds

\section{InTech Europe}

University Campus STeP Ri

Slavka Krautzeka 83/A

51000 Rijeka, Croatia

Phone: +385 (51) 770447

Fax: +385 (51) 686166

www.intechopen.com

\section{InTech China}

Unit 405, Office Block, Hotel Equatorial Shanghai

No.65, Yan An Road (West), Shanghai, 200040, China

中国上海市延安西路65号上海国际贵都大饭店办公楼405单元

Phone: +86-21-62489820

Fax: $+86-21-62489821$ 
(C) 2011 The Author(s). Licensee IntechOpen. This is an open access article distributed under the terms of the Creative Commons Attribution 3.0 License, which permits unrestricted use, distribution, and reproduction in any medium, provided the original work is properly cited. 